\title{
Protocol for the finishing stage
}

\section{J. Faure}

Former university lecturer; former head of DFO Dept, University of Toulouse, France. In private practice in Auch (France)

\begin{abstract}
Finishing is the most effective weapon in the battle against relapse. The choice of method depends on analyzing the type of relapse that is feared and the impact of aging, and on the help to be expected with retention.

The present article deals with the practical requirements of finishing: duration, pre-finishing assessment, final arch wire bending, possible occlusal buffing, and elastic vertical interarcade traction.

The theoretic protocol is illustrated by 3 cases followed up through finishing until appliance removal.

The stability of occlusal results of course depends on the accuracy and fineness of finishing, but also on overall treatment management: anterior dentition control, anchorage control during retraction period, and choice of devices and extractions.

Finishing can thus be said to be an important step - but one that begins on the first day of treatment.
\end{abstract}

\section{KEYWORDS}

Finishing, relapse, retention

\section{INTRODUCTION}

The choice of finishing strategy is indissociable from the analysis of relapse (and aging). The literature on relapse, however, provides little convincing information that might guide our approach to finishing 2,3,5-8, 10,11.

It is difficult, in adapting treatment, to distinguish the effects of retention or aging from "real relapse"; there is also often confusion between relapse and what we would call "treatment failure".

Relapse is often assessed simply by measuring crowding.
There are few studies with high levels of evidence.

Many studies implicated occasional effects $^{3}$, for example, of a certain treatment attitude, clinical choice, atypical growth, physiological or anatomic problem, etc. Such reports are often incomplete or low on level of evidence, but it is certainly helpful to take them on board in our therapeutic behavior.

Finishing differs from the main work in its timing (last touches), limited extent and, in our opinion, prime importance. Finishing is not a subsidiary but a major step.

Address for correspondence:

Jacques Faure

10, Place Lannes

Article received: 24-03-2015.

E-mail: faure_ja@club-internet.fr Accepted for publication: 27-07-2015.

This is an Open Access article distributed under the terms of the Creative Commons Attribution License (http://creativecommons.org/licenses/by/4.0), which permits unrestricted use, distribution, and reproduction in any medium, provided the original work is properly cited. 
A perfectly finished program requires precautions taken during the main work itself, as mistakes cannot always be rectified by finishing. "Perfect" finishing in orthodontics thus depends on: - initial treatment choices (control of anchorage, choice of extractions),

- and finishing itself.

In what follows, we shall briefly present our choices, the material procedures of finishing and their timing, richly illustrated from case reports.

We shall not enter into the intricacies of defining ideal occlusion, leaving the reader to refer to the criteria of the American Board of Orthodontics Grading System¹, which seem to command consensus in static terms.

\section{GENERAL LINES}

\section{Duration: 6 months}

Consecrating 6 months of treatment, with 4 or 5 appointments, is surely not excessive to deal in detail with static and dynamic occlusion: Poling ${ }^{9}$ advises 4 to 7 months. But this must not prolong the total treatment duration: to have 6 months for finishing, the other steps need to be performed as quickly as possible. Time-saving should begin from the outset of multibracket treatment, so as to achieve molar and canine class I relations with $2 \mathrm{~mm}$ incisor overbite, perfect alignment and leveling and closed spaces within a year and a half at most. The patient will then accept 6 months' finishing without objection.
Functional and dynamic imperatives and esthetic criteria, on the other hand, are not well-defined.

Our approach to perfect finishing consists in balancing the patient's maxillofacial architecture, especially anterior dentition, as well as possible, respecting the recognized rules of occlusal dynamics, and adopting a cautious attitude toward known threats to stability of treatment: third molar progression, anterior interdental dysharmony, late growth, etc. ${ }^{3}$

We shall then focus on our efforts to refine static occlusion.

To this aim, we present our finishing protocol.

Thus rapidly achieving good "prefinishing" occlusion is the first step toward perfectly "finished" occlusion.

\section{Dissociation between dental finishing/correction and preparation}

The transition to the finishing stage involves a break in the practitioner's concerns: where we had been concerned with the main aspects of objective occlusion, we now turn to what is more esthetically and functionally important: intercuspation, incisor alignment adjustment, artistic deformation, refining canine class I, adjusting the canine guide, etc. We need to look at what has been achieved, plan the finishing work 
and take account of how long treatment has already lasted and how much cooperation can be expected of the patient, in order to estimate how much time we can reasonably allow for finishing.

One major function of finishing is to test the quality of malocclusion correction. Otherwise, there is a risk of removing devices as soon as they seem to have triumphed over class II and signs of class I occlusion are observed. Unfortunately, however, this is often just a case of "Sunday bite" induced by the maxillomandibular elastic bands and, no sooner have the devices been removed than the patient slips right back into class II with severe overjet.

Unfortunately, in some cases the finishing stage cannot be strictly defined: finishing work on the arch is required during the anterior retraction stage (case $n^{\circ} 1$ ) to help correct malocclusion.

\section{Analysis of occlusion status and finishing strategy}

In our opinion, occlusion analysis does not require a complicated clinical form, but does include:
- static aspect, with articulating paper to trace the numerous contacts and intercuspal balance;

- dynamic aspect, with systematic examination of lateralities and especially propulsion.

For us, analysis of occlusion defects is in strict parallel to correction, systematizing intervention and avoiding a lot of points getting overlooked.

A radiological check-up is essential. A panoramic view serves to check tooth parallelism and excessive interroot space if implant sites are to be prepared. It also avoids corono-radicular angles being detected too late when they might lead to threatening proximities: treatment in this case (figs 1-6) of severe class III, ended with perfect occlusion, with a slight linear and angular mandibular compensation that had to be accepted, and maxillary decompensation that doubtless ensured anterior stability; systematic end-of-treatment panoramic unfortunately showed severe mandibular canine angulation; it was too late to correct the tooth axes to achieve compromise after the devices had been removed.

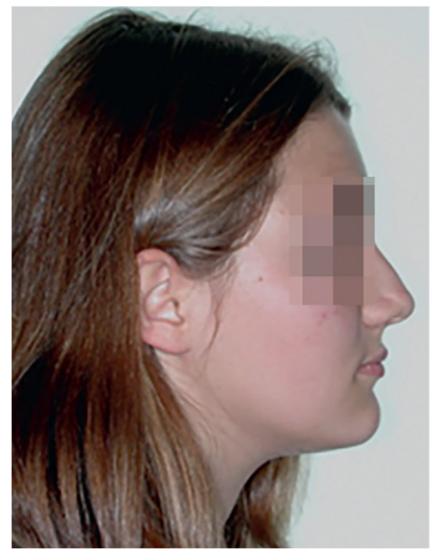

a

Figure 1

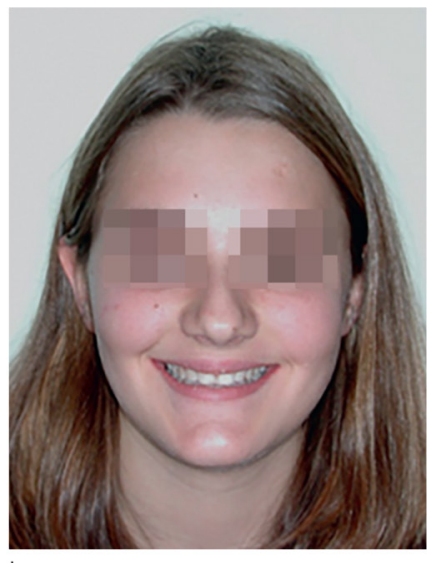

b

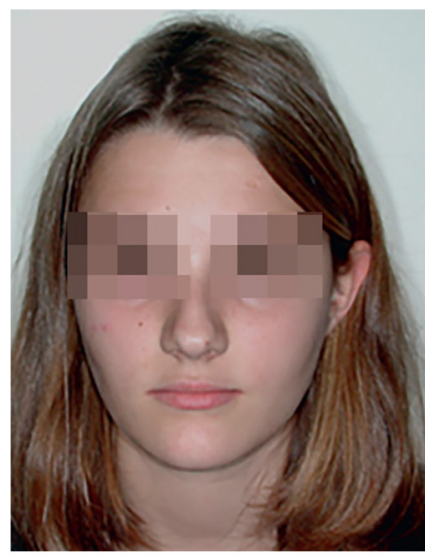

c

a, b, c: Lateral, three-quarter smile and frontal views. Fanny D., born Jan. 1988. End of treatment, 14 yrs 10 mo. 


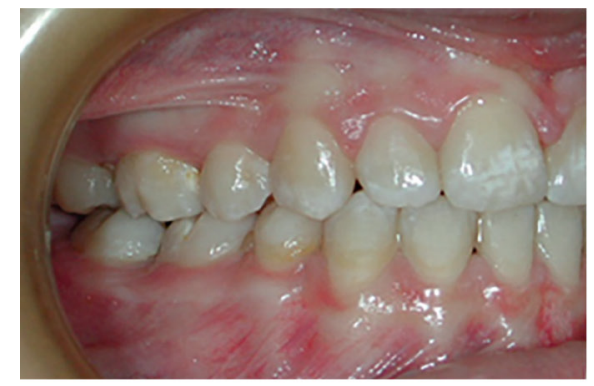

a

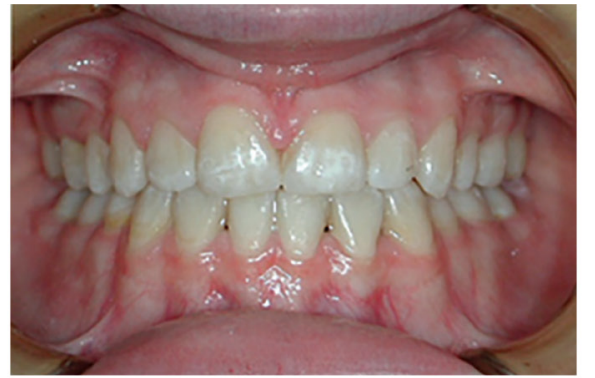

b

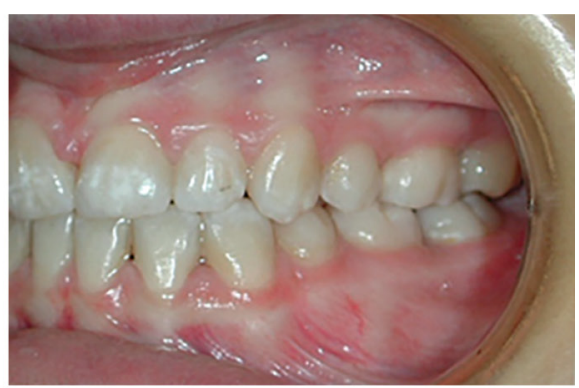

C

Figure 2

a, b, c: Right, frontal and left intraoral vestibular views. Fanny D., born Jan. 1988. End of treatment, Nov. 2002, 14 yrs 10 mo.

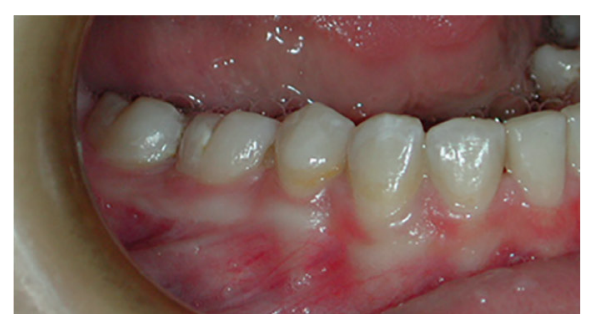

a

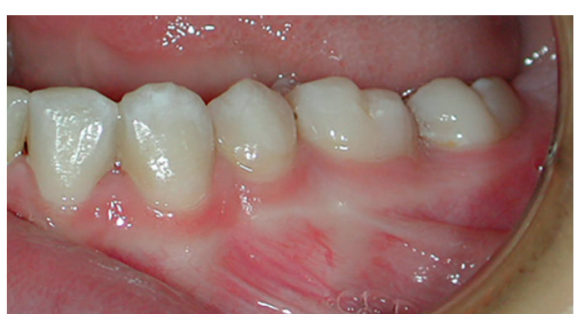

b

Figure 3

a, b: Intraoral views, canine region close-up, checking alignment, leveling and coronary axes.

Fanny D., born Jan. 1988. End of treatment, Nov. 2002, 14 yrs 10 mo.

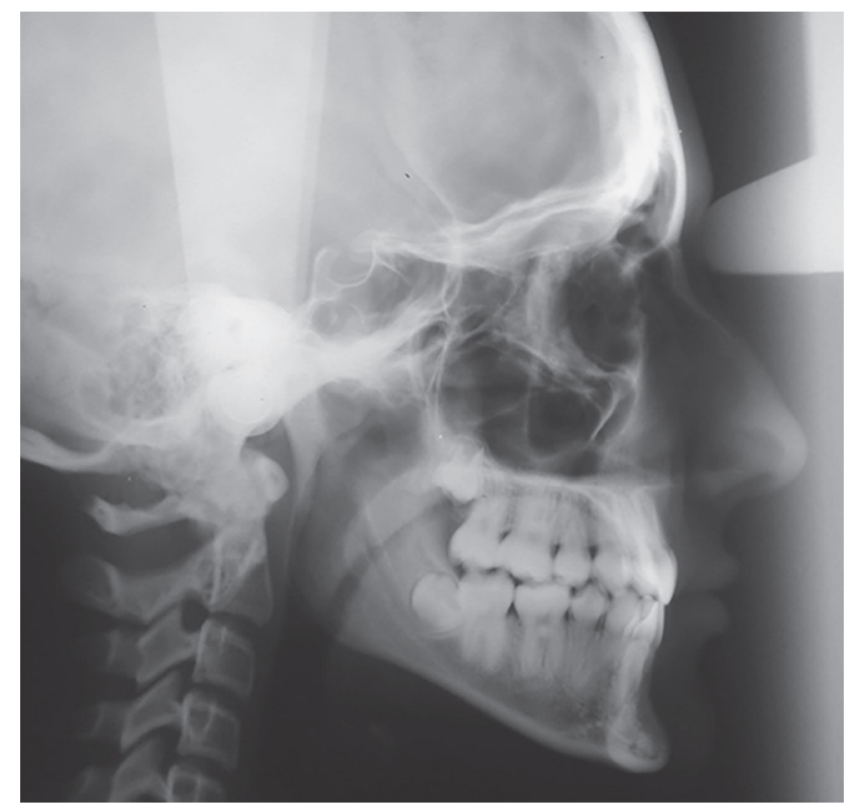

Figure 4

Lateral teleradiograph. Fanny D., born Jan. 1988. End of treatment, Nov. 2002, 14 yrs 10 mo. 


\section{Fanny D. née le $26 / 1 / 88$. Fin de traitement, 11/02, 14a 10m}

$\begin{array}{lc}\text { FMIA } & 67 \\ \text { FMA } & 25 \\ \text { IMPA } & 88 \\ \text { SNA } & 80 \\ \text { SNB } & 81 \\ \text { ANB } & -1 \\ \text { AoBo } & -4 \\ \text { Plan d'Occ } & 11 \\ \text { Angle Z } & 80 \\ \text { Upper lip } & 14 \\ \text { Total chin } & 9 \\ \text { Ht Faciale Post } & 44.5 \\ \text { Ht Faciale Ant } & 62 \\ \text { Index Post/ Ant } & 0.72\end{array}$

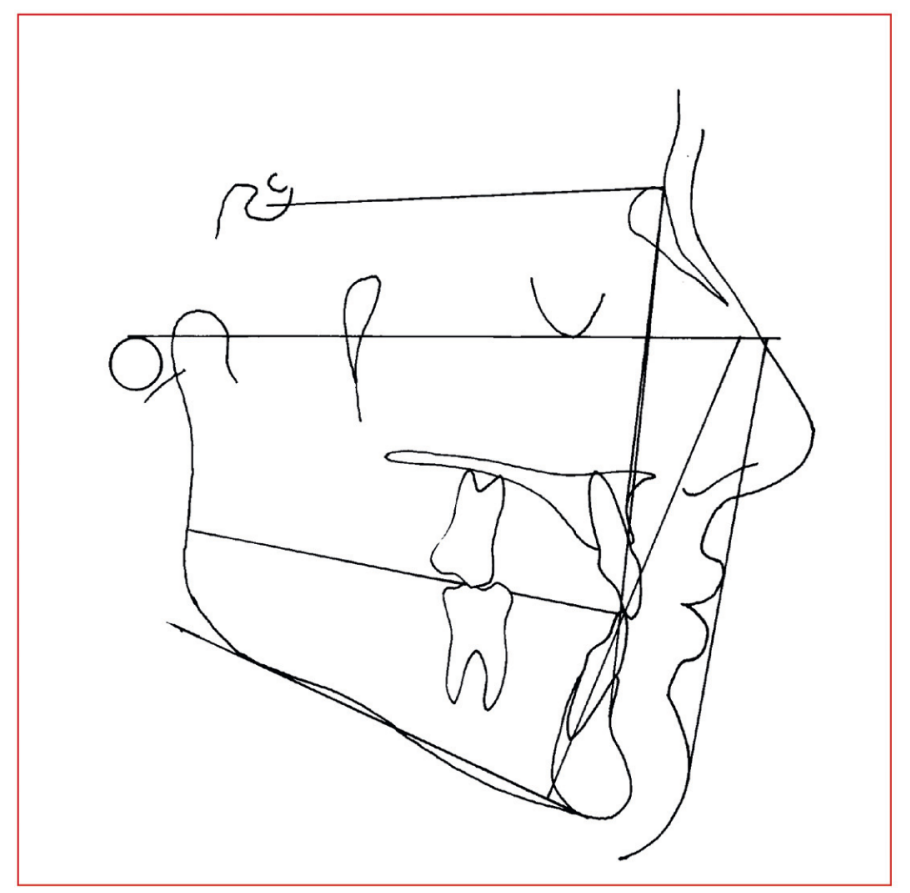

SNA

SNB

ANB $\quad-1$

SND $\quad 80$

1/NAmm $\quad 4.5$

1/NA ${ }^{\circ} \quad 21$

1/NBmm 2

$1 / \mathrm{NB}^{\circ} \quad 16$

Pog/NB 5

$1 / 1$

Occl/ SN $\quad 13.5$

GoGn/SN 26

SE 62

SL

18.5

Figure 5

Diagram and Steiner and Tweed analyses. Fanny D., born Jan. 1988. End of treatment, Nov. 2002, 14 yrs 10 mo Fanny D., born Jan. 26, 1988. End of treatment, Nov. 2002, 14 yrs 10 mo

Plan d'Occ: Occ plane / Ht Faciale Post: Post facial height / Ht Faciale Ant: Ant facial height

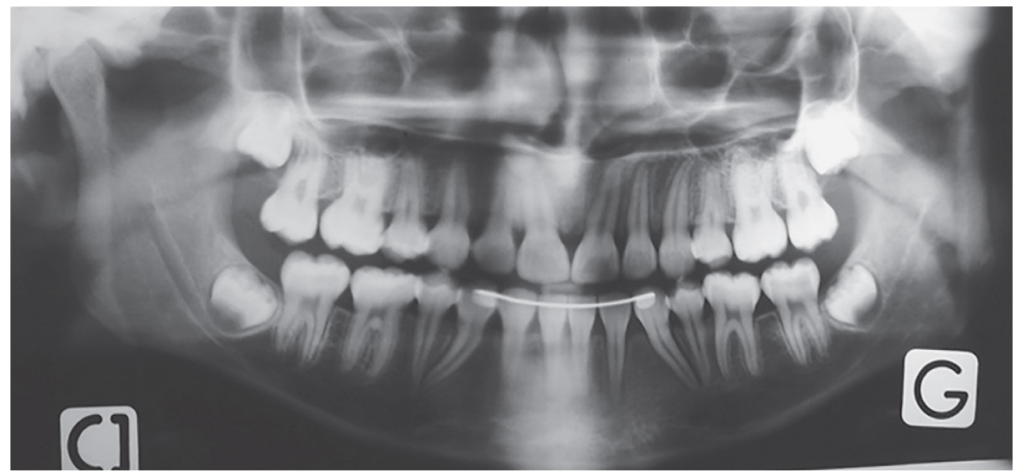

Figure 6

Panoramic view. Fanny D., born Jan. 1988. End of treatment, Nov. 2002, 14 yrs 10 mo. 


\section{Main treatment procedures}

The main therapeutic procedures comprise:

- elastic vertical traction, worn permanently. Traction should be exerted on the arch (welded brass spurs or pinched stops) rather than on this or that tooth: unitary dental displacement is governed by the arch (especially $2^{\text {nd }}$ order shaping), whereas maxillomandibular traction controls extensive gaps (dental group or arcade sector or half-arcade).

Arch anchorages may seem to hinder implementing shaping at the same site, but this is not actually true: angulations can be introduced on either side of the weld without putting its at risk, to perform a step, for example (fig. 7).

- Occlusal sharpening regularizes anatomic abnormalities hindering occlusion. Occlusal adjustment should not replace finishing, often by inducing dental intrusion or extrusion in case of gauge error; buffing is indicated in coronary dysmorphism causing a gap or occlusal trauma.

- Shaping on .019 x.026 arch, by 139type forceps, is certainly the most precise method, enabling any practitioner to perform a release on the arch with $0.2 \mathrm{~mm}$ precision; it is the method we prefer.

Poling ${ }^{9}$ underlined the risk of weakening the arch at the torsion points, but we think the risk of fracture is virtually non-existent.

Some authors recommend an alternative solution, ungluing and regluing the bracket when badly positioned. This is attractive, being in line with the philosophy of a straight arch, but is open to theoretical and practical objections:

- If 13 shows $0.5 \mathrm{~mm}$ extrusion and $5^{\circ}$ tip-forward, the bracket should be released and reglued with a $0.5-\mathrm{mm}$ shorter gauge and in-built $5^{\circ}$ tip-back. The problem is that, once the original bracket has been released, we have no reference for positioning the new one!

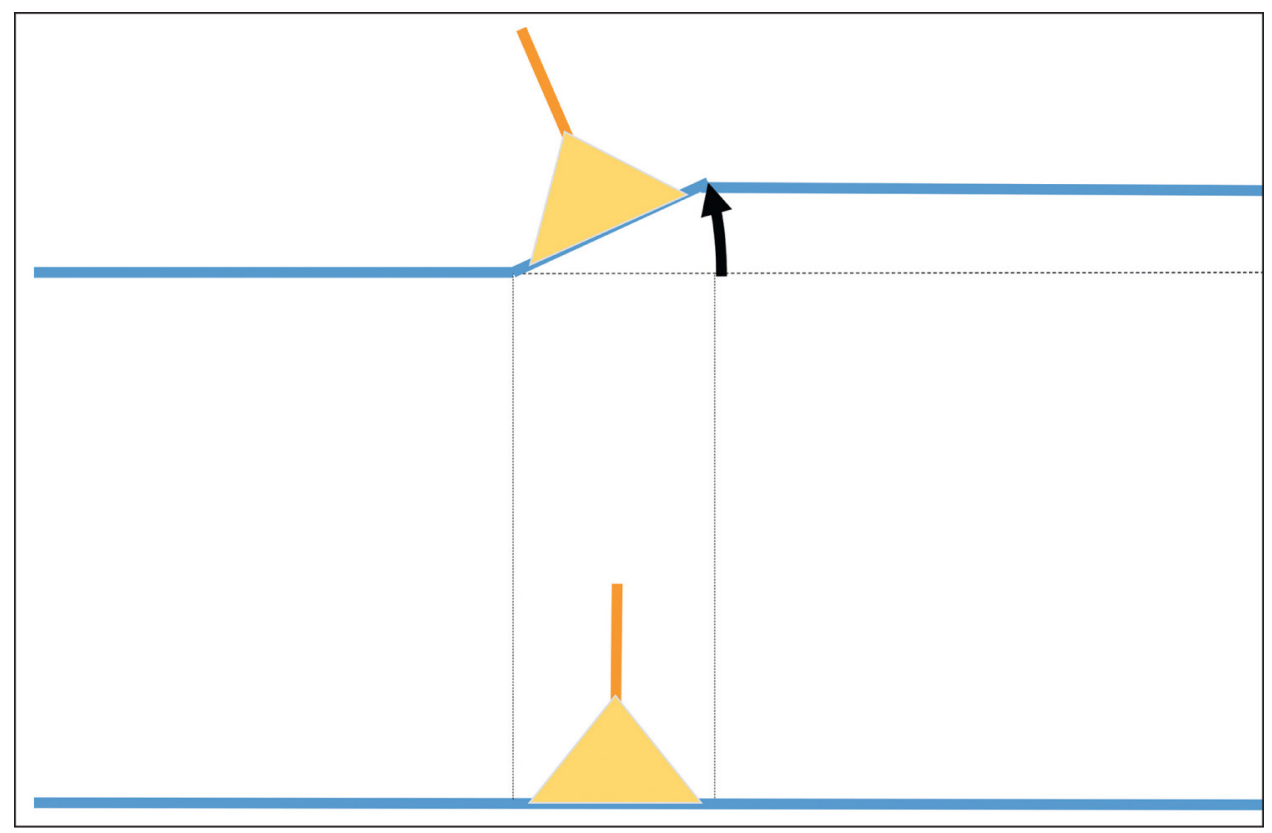

Figure 7

Introducing a step in an interdental space already bearing a welded spur: angles mesial and distal to the weld. 
- Experience shows that practitioners usually glue the second bracket back precisely in the position of the first, exactly matching the anatomic data at first fitting 9 .

- The smaller the desired change in position, the less the precision of correction by regluing .

We consider the "ungluing-regluing" method indicated only for big mistakes in positioning (>1.5 mm), which almost never happen.

Another argument supports the choice of "pliers shaping" rather than "ungluing-gluing" as recommended by some: this is the spread of selfligating brackets (which we have used for many years now); time saving compared to ablating and replacing an arch now leaves more time for "touching up" and a strategy of rational finishing (notably respecting the rule of the 3 orders) conducted methodically and rigorously. No-one would hesitate now to remove a terminal arch with a single application of pliers.

\section{CHECKS}

At each stage, of course, we check the result of the previous stage, statically and dynamically; the protocol can be revised at any time.

\section{Hierarchy of interventions on the arch}

Intervention should follow a rigorous protocol. Three chronological rules are to be observed

- intervention according to arcade: first intervention on mandibular arcade, then on maxillary arcade;

- intervention according to order: first, $1^{\text {st }}$ order; second, $2^{\text {nd }}$ order; third, $3^{\text {rd }}$ order;
- intervention according to extension or location: first intervention for a general problem; second intervention for a localized problem.

For example, in case of bilateral tip-to-tip, with clear crossed occlusion only in 14/44-45 and 25/35-36, we begin by overall maxillary expansion (and possibly mandibular contraction); then secondly we correct remaining crossed occlusions by individual inset/offset procedures.

\section{FINISHING ARCHES}

Some schools recommend "loosening the bridle" during finishing, using more elastic material and under-sized arches in titanium or nickel-titanium of $.018 \times .025$ or $.016 \times .022$ section or round .016 or .014 arches, in the hope that nature will finish occlusion.
In contrast, we think that, near the end of treatment, position control needs to be maintained or increased to correct the last remaining little imperfections.

Finishing thus uses $.019 \times .026$ nickelchromium arches in $95 \%$ of cases. 


\section{Full-groove steel arches, section $.022 \times .028$}

We only use full-groove arches for severe general problems of arcade shape.

Transversally, bilateral crossed occlusion problems can be easily resolved by maxillary expansion or mandibular contraction or both, with either a $.022 \times .028$ active arch or 2 arches.

Vertically, in case of strong mandibular Spee curve, a full-groove arch solves the problem quickly.

\section{Steel arch, section $.019 \times .026$}

A $.019 \times .026$ arch has the advantage of enabling most finishing corrections to be performed in a single procedure, without risk of bracket detachment.

It is possible to introduce $1^{\text {st }}$ or $2^{\text {nd }}$ order shaping in the arch up to 1 to $1.5 \mathrm{~mm}$ (step-up/step-down or inset/offset ).
Shaping on this scale with a fullgroove arch would inevitably lead to detachment.

But it can also be introduced in 2 stages (fig. 8: $0.75 \mathrm{~mm}$ step, increased to $1.5 \mathrm{~mm}$ at next appointment).

The $.019 \times .026$ arch is the optimal compromise between malleability and elasticity for occasional finishing.

Moreover, loss of position control is minimal with a.019 $\times .026$ arch in a $.022 \times .028$ groove: negligible for axial rotation or mesio-distal tilt, and only $7^{\circ}$ for torque.

If the power of a full-groove arch is needed (e.g., strong Spee curve), it should be introduced first, and then, for occasional finishing, either revert to a $.019 \times .026$ arch or finish with a full-groove arch in 2 stages (cf. below and fig. 8).

\section{FREQUENCY OF INTERVENTION}

The frequency of finishing operations depends on the large number of occlusal contacts. Ranking according to order is as follows:

\section{$2^{\text {nd }}$ order: approx. $\mathbf{7 0 \%}$}

These are general interventions, notably correction of strong Spee curves; they are often occasional, especially to intrude/extrude single teeth in the lateral sectors (step-up or stepdown); axial corrections (tip back/tip forward, with 2 identical consecutive steps) are more frequent in the anterior sector, for esthetic reasons, optimizing the "esthetic shaping" already included in the brackets.

\section{$1^{\text {st }}$ order: approx. $30 \%$}

General interventions (arch expansion/contraction) are frequent.

Occasional interventions are rarer: slight vestibular or palatal displacement loffset + inset " or inset + offset), to correct, for example, an overly vestibular lateral, incisor (residual class II division 2 occlusion), or axial rotation due to general gluing error (inset + inset or offset + offset ).

\section{$3^{\text {rd }}$ order: exceptional}

Third-order intervention is very rare in our practice. Torque control with a $.019 x$ .026 arch in a $.022 \times .028$ groove is excellent, with just $7^{\circ}$ play or loss of control. 


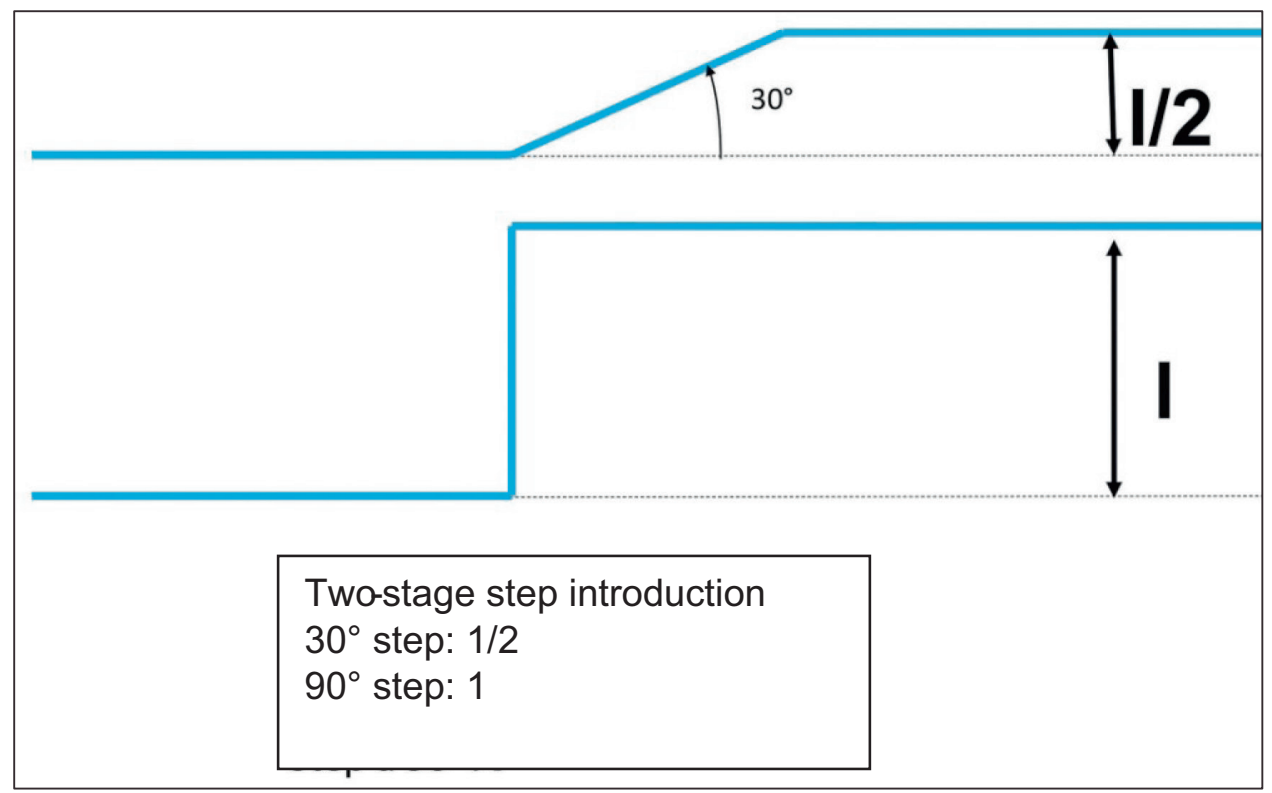

Figure 8

Introducing a large step in 2 stages: $30^{\circ}$ then $90^{\circ}(\mathrm{h}=0.75 \mathrm{~mm}$ then $1.5 \mathrm{~mm})$.

With Roth prescription, a severely retracted superior central incisor at risk of "under-version" ends up at $14^{\circ}$ minus $7^{\circ}=+7^{\circ}\left(+14^{\circ}\right.$ : incorporated Roth torque; $-7^{\circ}$ loss of undersizing control); residual version greatly exceeds the natural version of $1^{\circ}$ to $2^{\circ} 4$.

These rare interventions usually concern incisor groups, to achieve angular under-compensation or overdecompensation. What is sought is a final position in angular over-decompensation: in severe skeletal class II, for example, final slight incisor angular superior protrusion $\left(+3^{\circ}\right.$ to $\left.+5^{\circ}\right)$ and slight inferior retrusion $\left(-3^{\circ}\right.$ to $\left.-5^{\circ}\right)$, or class III compensation, is recom- mended by some authors (Planché, Andrews) to guard against any slight tendency to relapse. Such angular overdecompensation comes obviously at the price of linear over-compensation; likewise, over-decompensation of bilabioversion requires reduced superior and inferior incisor torque.

Occasional intervention may exceptionally be needed to correct ectopic included canines that have undergone difficult traction (e.g., vestibular maxillary canines) to avoid fenestration. In such cases, it is wise to provide "torque breakers" to soften, the impact of torque correction. 


\section{CONCLUSION}

A long finishing stage using pliers provides perfect static occlusion, rigorous intercuspation and canine and molar class I relations, while ensuring functional and esthetic excellence.

This stage is not enough in itself to ensure stability, which depends also on the architectural balance of the face and anterior dentition: i.e., the critical therapeutic choices regarding extraction and mechanics, anchorage, final incisor positioning and functional balance, etc. Thus, finishing begins on the day when the brackets are fitted; the first steps are critical as initial mistakes preclude perfect occlusion, and any delay leaves less time for finishing.

Even with perfect treatment strategy and rigorous finishing, definitive stability is not guaranteed, and final occlusion may "wobble", either for functional reasons (recurrent dysfunction) or simply with aging.

Even so, a rigorous protocol, close attention and time spent on finishing help conjure the specter of relapse, or at least reduce its frequency and severity.

\section{CASE 1}

\section{Diagnosis}

Manon G. consulted in May 2011 at the age of 13 years 8 months. Her face presented as class II hyperdivergent; intraoral examination, however, found molar class I with only moderate overjet (figs 9-12). Cephalometry

confirmed the severity of skeletal class II, "borderline surgical", and the degree of linear and especially angular compensation trying to hide it. Bilabioversion related to DMD was superimposed on class II (T1 and T2) linear compensation.

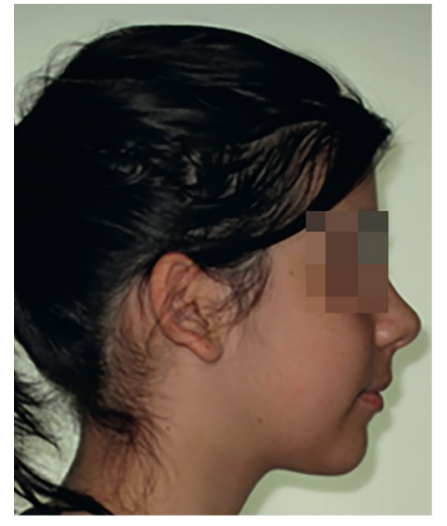

a

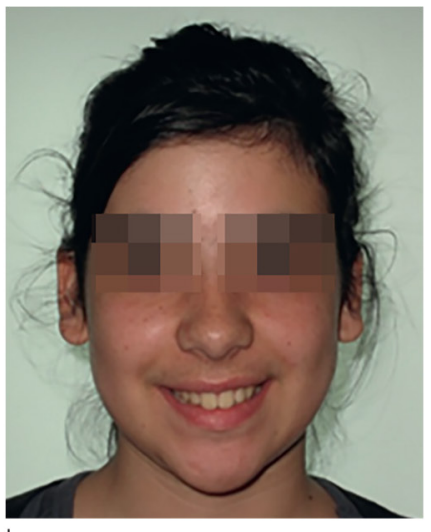

b

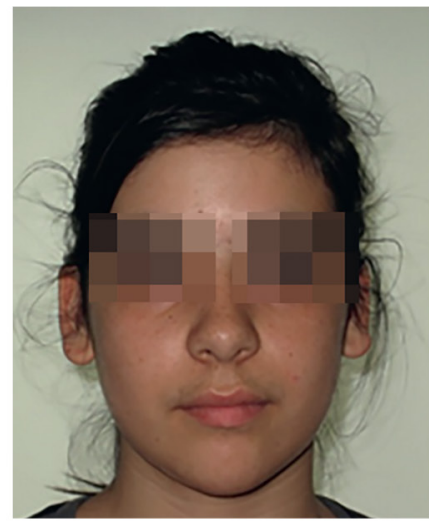

C

Figure 9

a, b, c: Lateral, smile and frontal views. Nov. 5 (13 yrs 8mo); $1^{\text {st }}$ documents. 


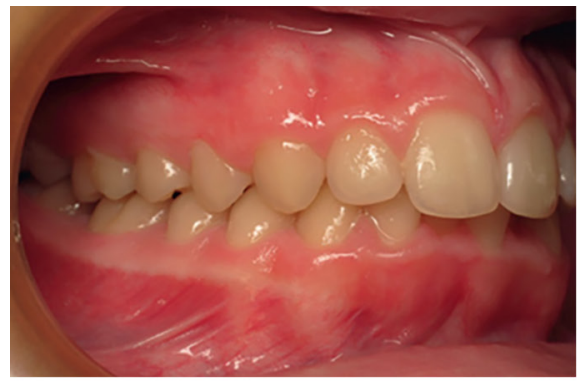

a

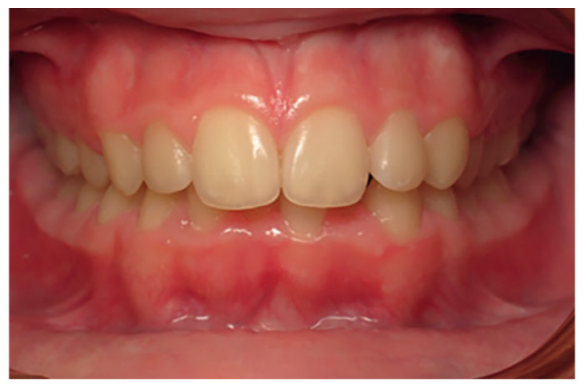

b

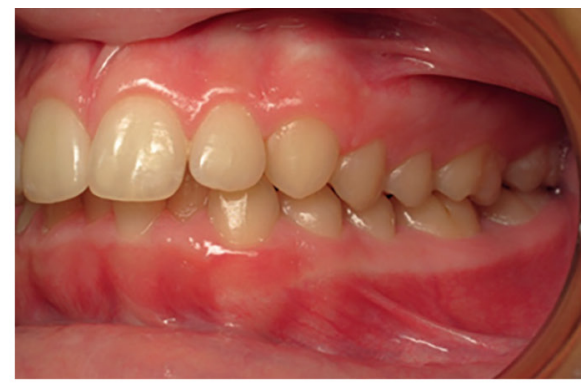

C

Figure 10

$a, b, c:$ Right, frontal and left intraoral views. Nov. 5 (13 yrs 8mo); $1^{\text {st }}$ documents.

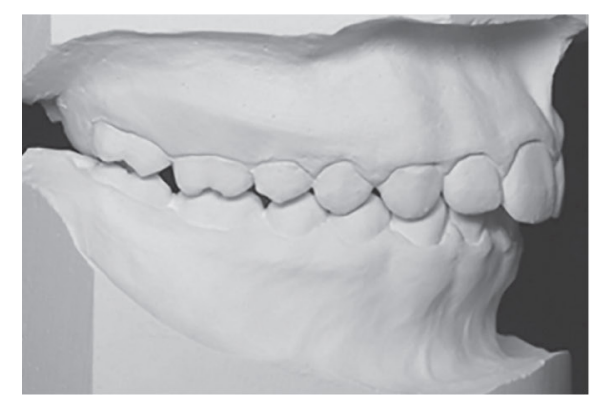

a

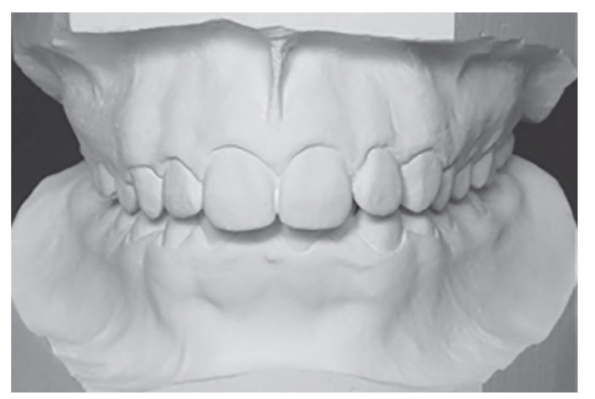

b

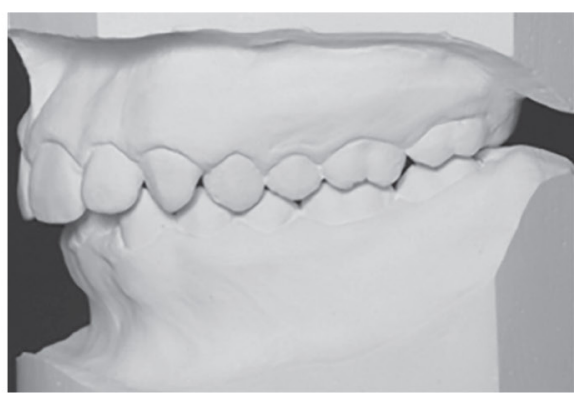

C

Figure 11

$a, b, c$ : Molds, right, frontal and left views. Nov. 5 (13 yrs 8mo); $1^{\text {st }}$ documents.

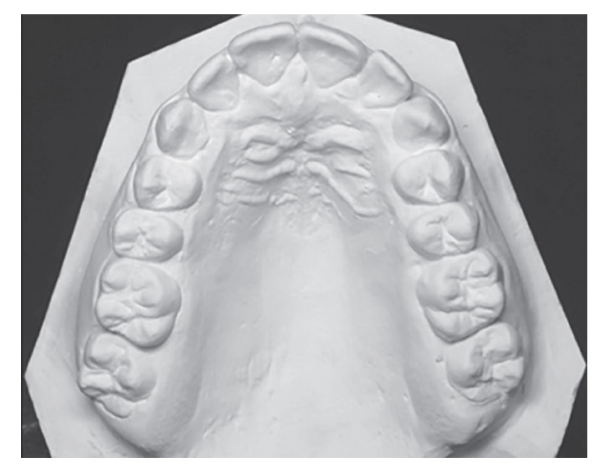

a

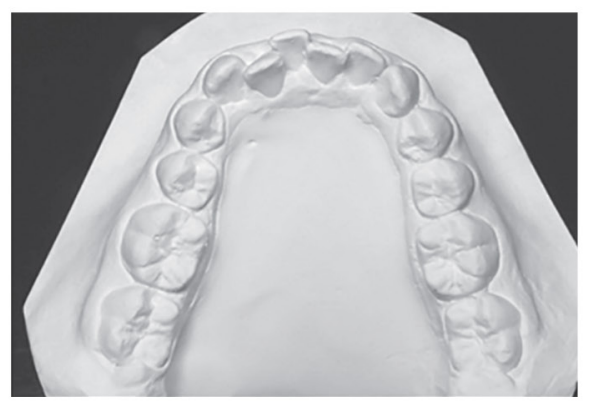

b

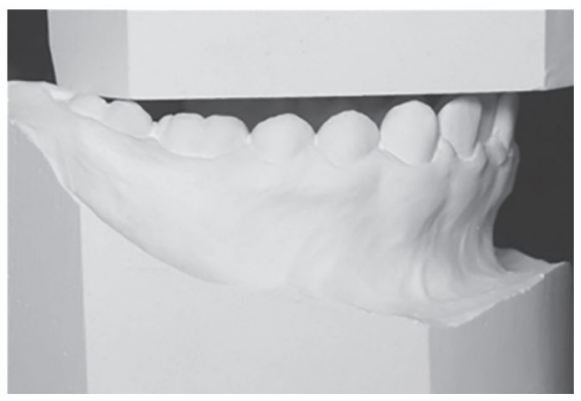

C

Figure 12

a, b, c: Occlusal maxillary and mandibular views and Spee curve. 5 (13 yrs 8mo); $1^{\text {st }}$ documents. 


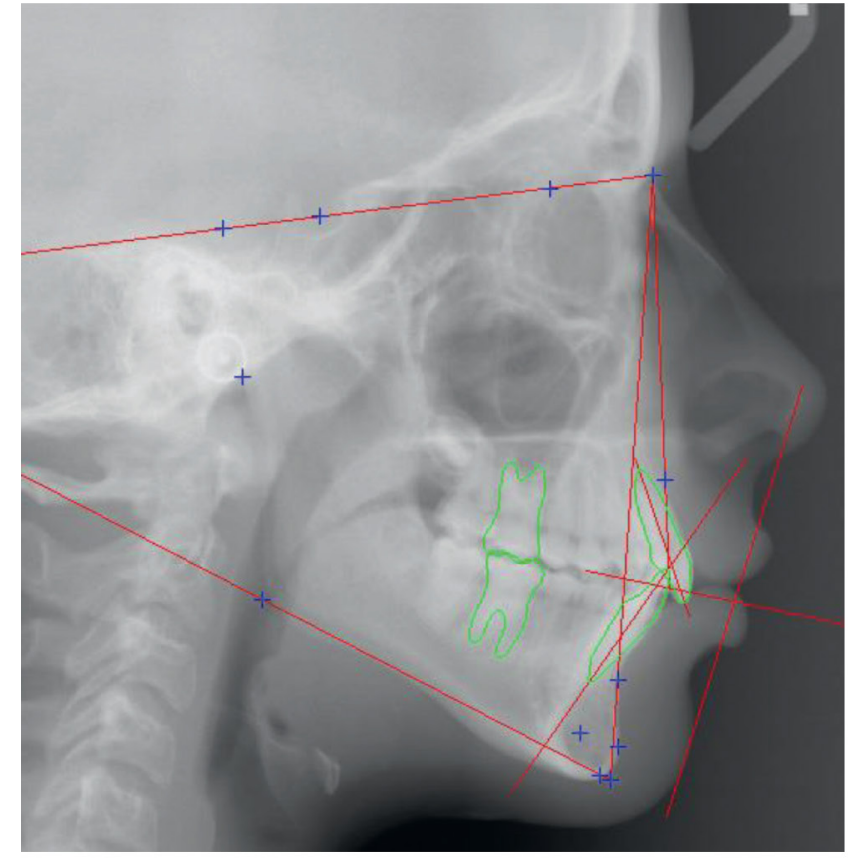

a

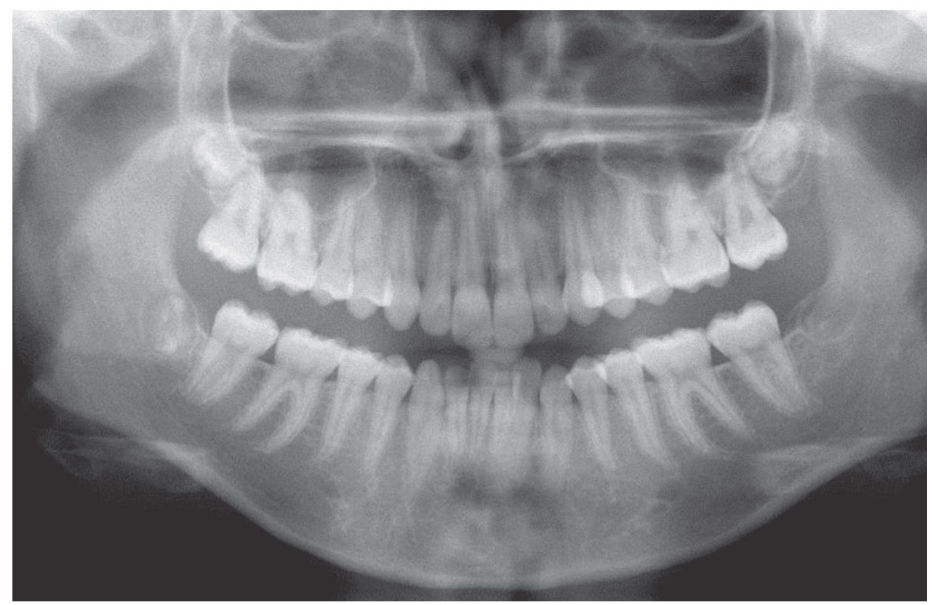

b

Figure 13

a, b: Teleradiograph with Steiner lines and panoramic view. 5 (13 yrs 8mo); $1^{\text {st }}$ documents.

\section{Treatment plan}

The incisor positioning objective involved a very slight compromise to balance a difficult "frame", at the cost of heavy devices (miniscrews to avoid any loss of anchorage) in a difficult case (figs 14 and 15).

Achieving perfectly finished stable occlusion required extreme mechani- cal precautions to maintain anchorage, enabling rigorous control of skeletal and dental class II correction and correction of linear bilabioversion.

We used straight arch attachments, with.022 x .028 groove, Roth prescription and inbuilt $-10^{\circ}$ and $-15^{\circ}$ tip--back on the mandibular molars (passive self-ligating brackets). 


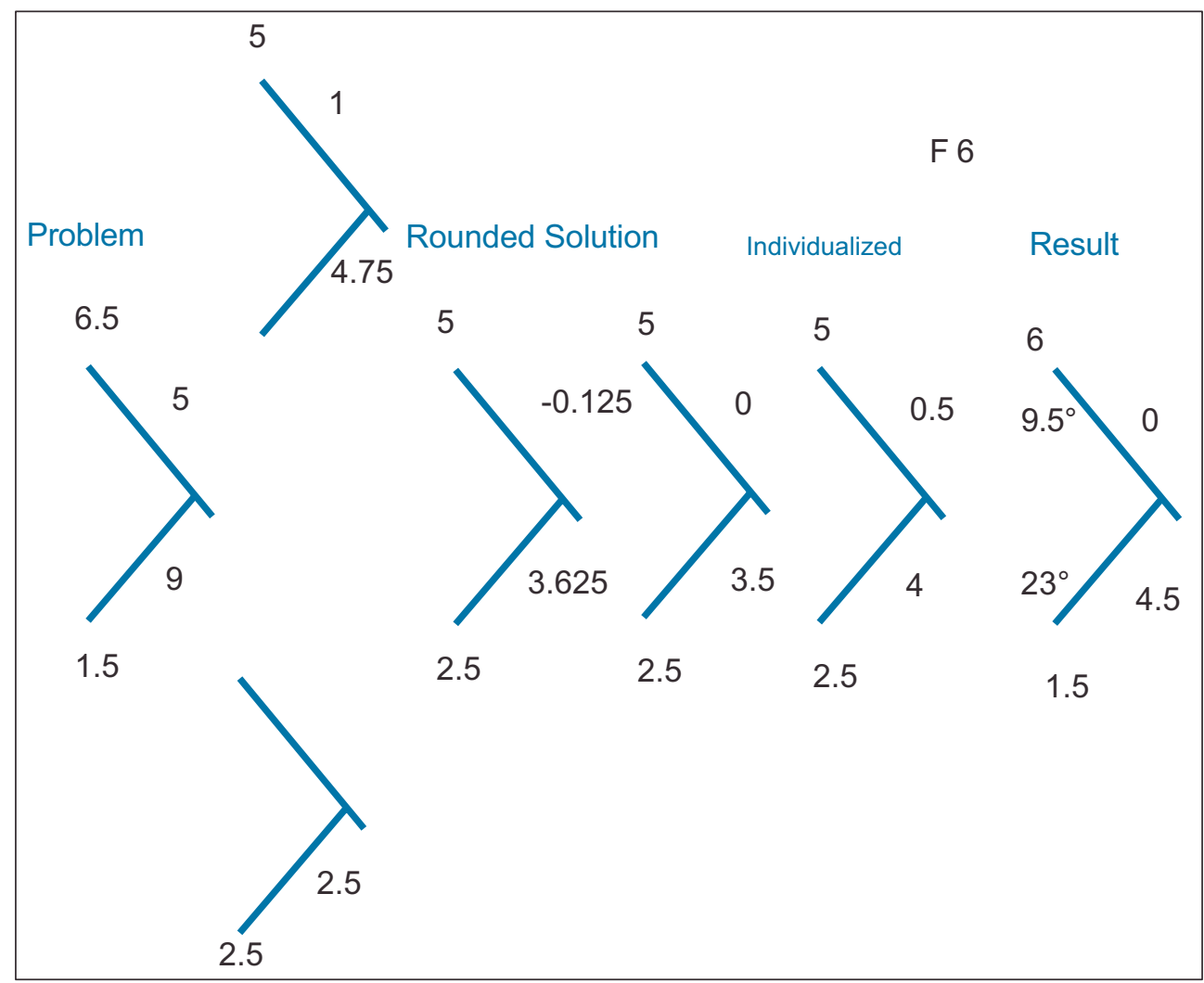

Figure 14

Steiner chevrons.

\begin{tabular}{|l|l|l|}
\hline Discrepancy & -4 & \\
Spee curve & -1 & \\
Relocation i & $-11->-10$ & \\
Extraction & $-5->0$ & +15 \\
IMT II & & \\
Relocation 6 & & \\
Total & $-21->-15$ & +15 \\
\hline
\end{tabular}

Available space $\quad 0$

Diameter of $8 s \quad-22$

Present deficit $\quad-22$

Residual growth* $\quad+9.5$

Anchorage loss $\quad+4$

Expected deficit $\quad-8.5$

- According to: Space gain = 33-1.722xage

Figure 15

Steiner "box" and posterior space "box". 


\section{Treatment and finishing:}

\section{Aug. 2011 (13yrs 11mo) - Aug. 2014 (16yrs 11mo)}

The degree of anterior retraction to be achieved, especially on the maxilla, required early finishing operations, during the actual retraction stage, although we would usually try to avoid this. Finishing will optimally adjust occlusion when malocclusion correction has been completed.
Early finishing operations were needed as incisor retraction was blocked by closed bite (figs 16 and 17), due to slight excess of maxillary incisors gauge and arcade flexion induced by the retraction imposed $(.019 \times .026$ arch); reshaping comprised 2 nd order action (maxillary incisor intrusion, especially of 11-21) and radiculo-palatal torque (figs 18-21).

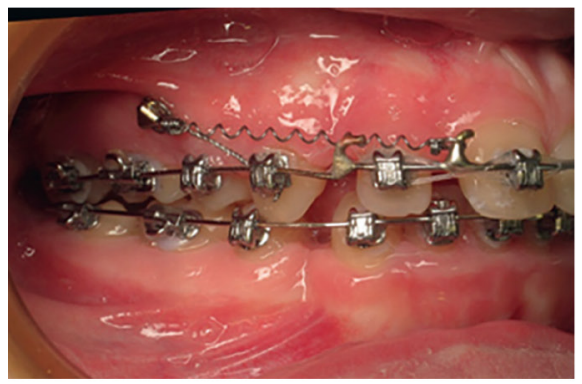

a

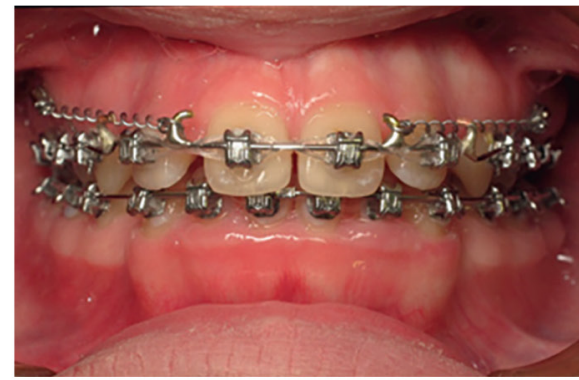

Figure 16

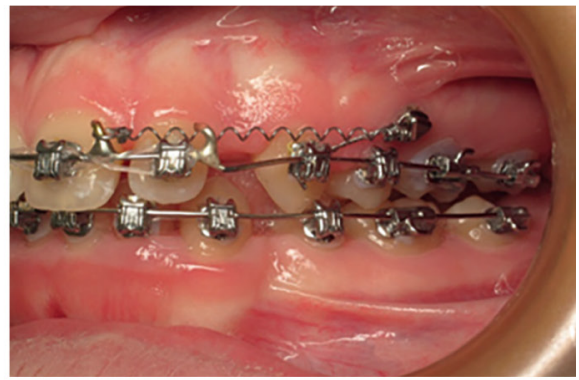

C

a, b, c Right, frontal and left vestibular intra-oral views, Aug. 2012 (14yrs 11mo); direct mechanical incisor retraction blocked by closed bite.

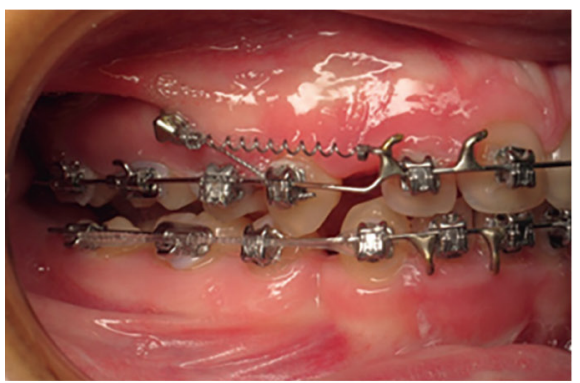

a

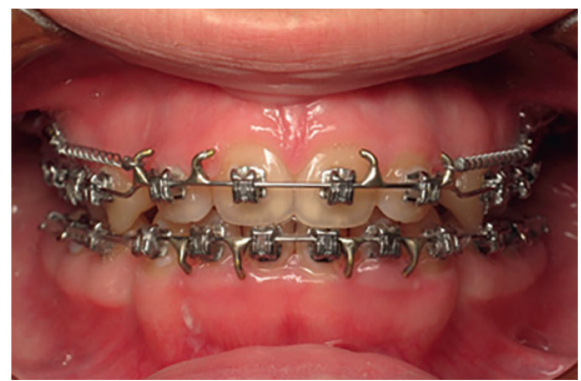

Figure 17

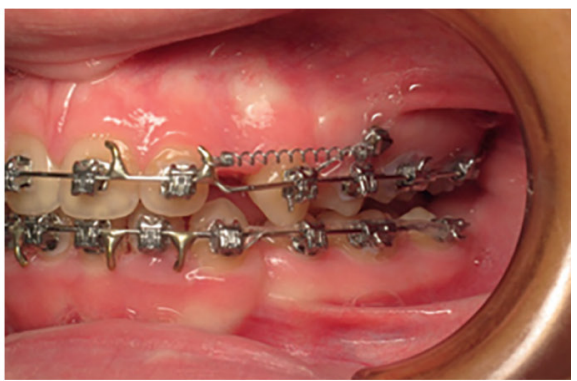

C

a, b, c Right, frontal and left vestibular intra-oral views, Aug. 2012 (14yrs 11mo); incisor retraction: introduction of step-up 3-2.

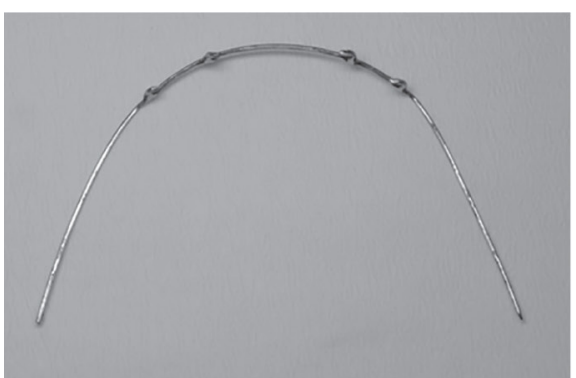

a

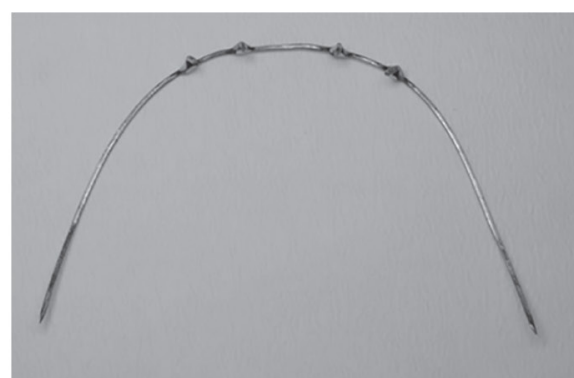

Figure 18 b

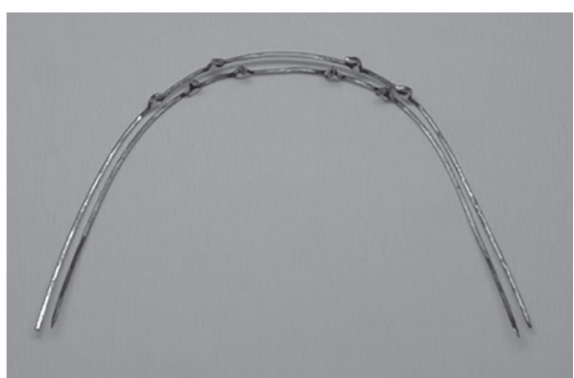

C

a, b, c Maxillary, mandibular arches and coordination. 


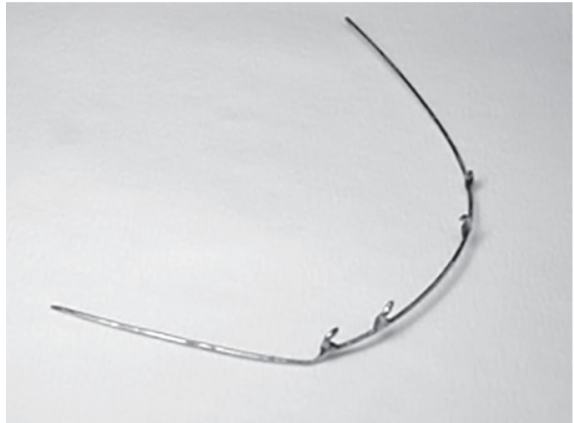

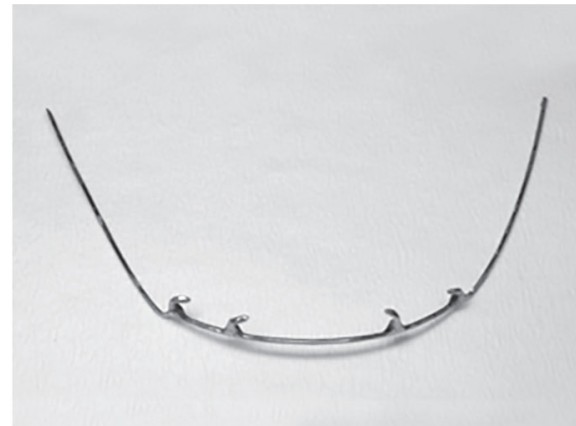

b

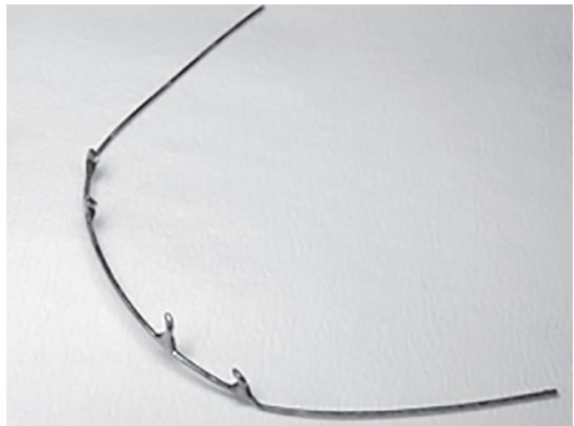

C

Figure 19

$a, b, c$ : Maxillary arch seen from right, front and left.

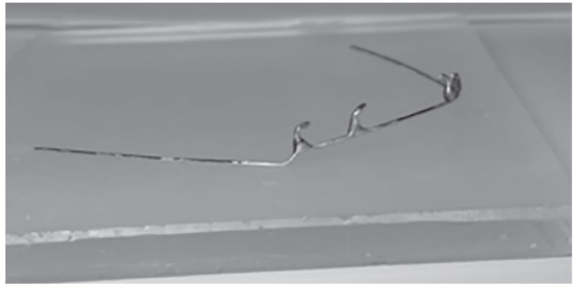

a

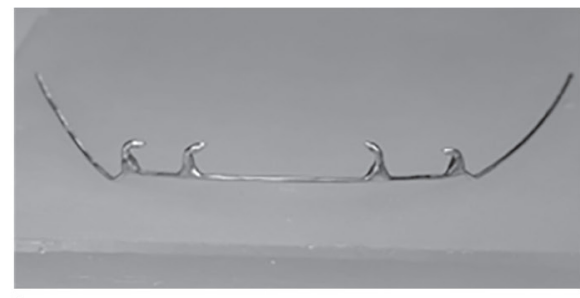

b

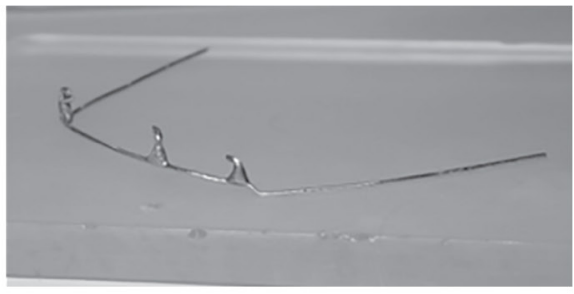

Figure 20

a, b, c: Maxillary arch, close-up of flat part, seen from right, front and left.

- Intrusion step: intrusion of the 4 incisors

- Arch angulation: stronger intrusion of 11-21

- Radiculo-palatal torque on the 4 incisors

Torque: $+10^{\circ}$

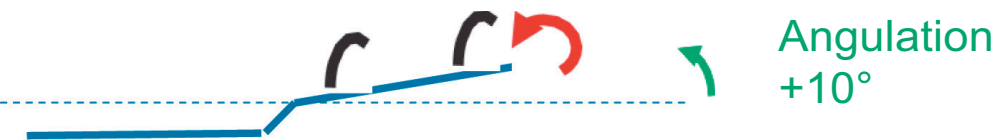

Figure 21

Diagram of mechanical analysis.

Retraction was completed without difficulty, and individual finishings were added.

Final documents (figs 22-26) show over-decompensation:

- of bilabioversion (especially angular);
- and of initial class II compensation: mandibular incisor reduced from $31^{\circ}-9 \mathrm{~mm}$ to $23^{\circ}-4.5 \mathrm{~mm}$ (fig. 27).

Final (figs 22-26 and Tables 1-2) and post-treatment documents show occlusion stability. 


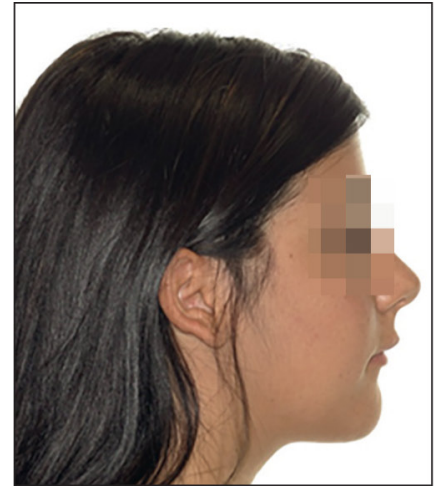

a

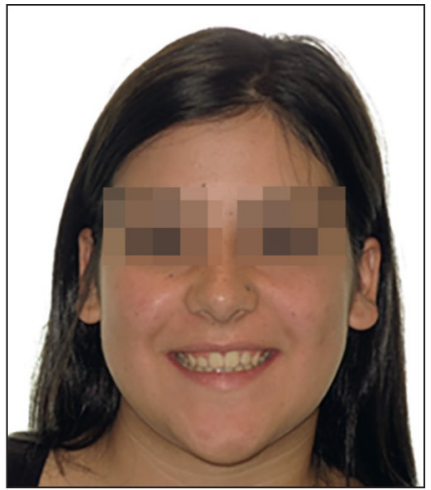

Figure 22

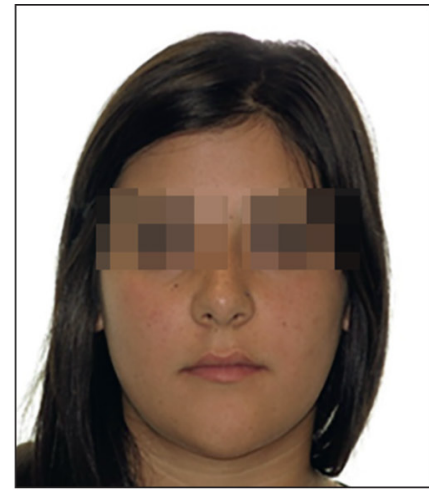

C

a, b, c: Lateral, smile and frontal views; Aug. 2014 (16yrs 11mo); ablation.

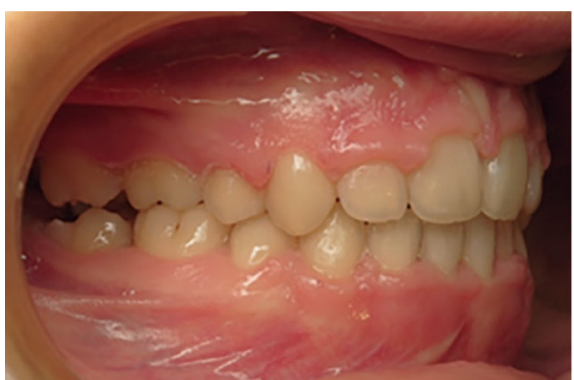

a

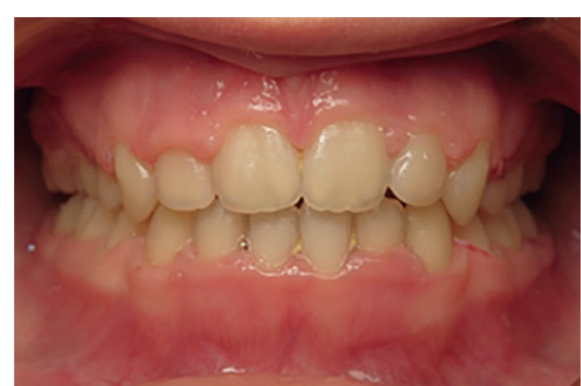

Figure 23

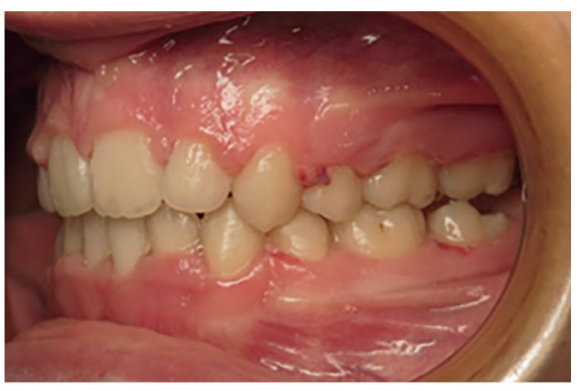

$\mathrm{C}$

a, b, c: Right, frontal and left vestibular intra-oral views; Aug. 2014 (16yrs 11mo); ablation.

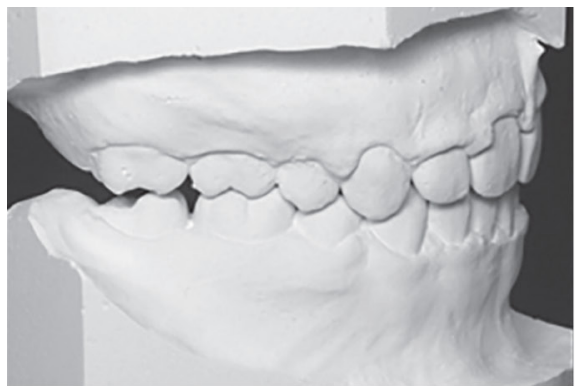

a

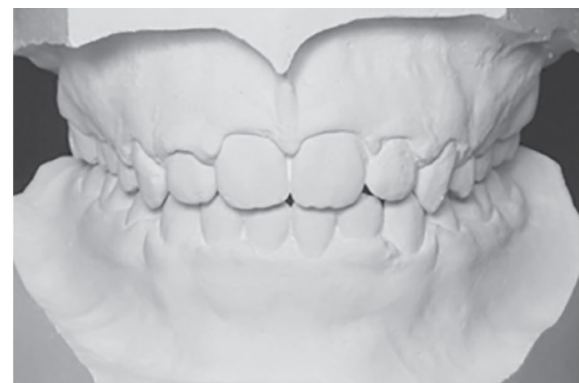

Figure 24

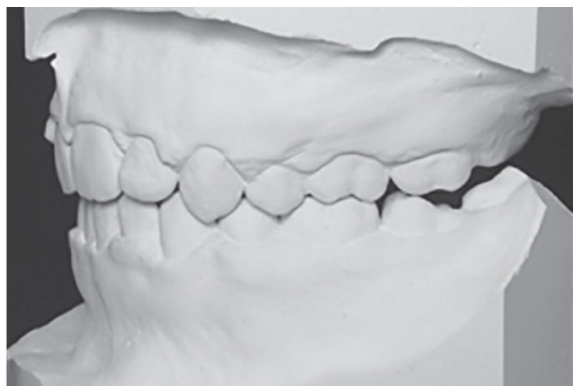

$\mathrm{C}$

a, b, c: Molds: Right, frontal and left vestibular views; Aug. 2014 (16yrs 11mo); ablation.

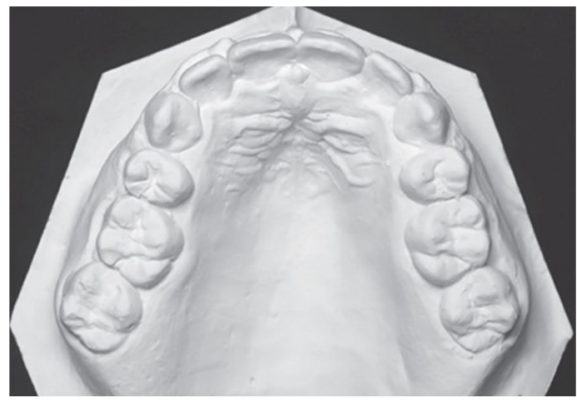

a

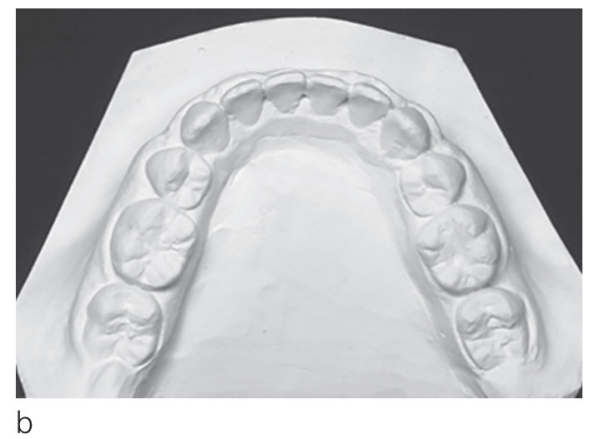

$\mathrm{b}$

Figure 25

a, b: Molds: occlusal, maxillary and mandibular views; Aug. 2014 (16yrs 11mo); ablation. 

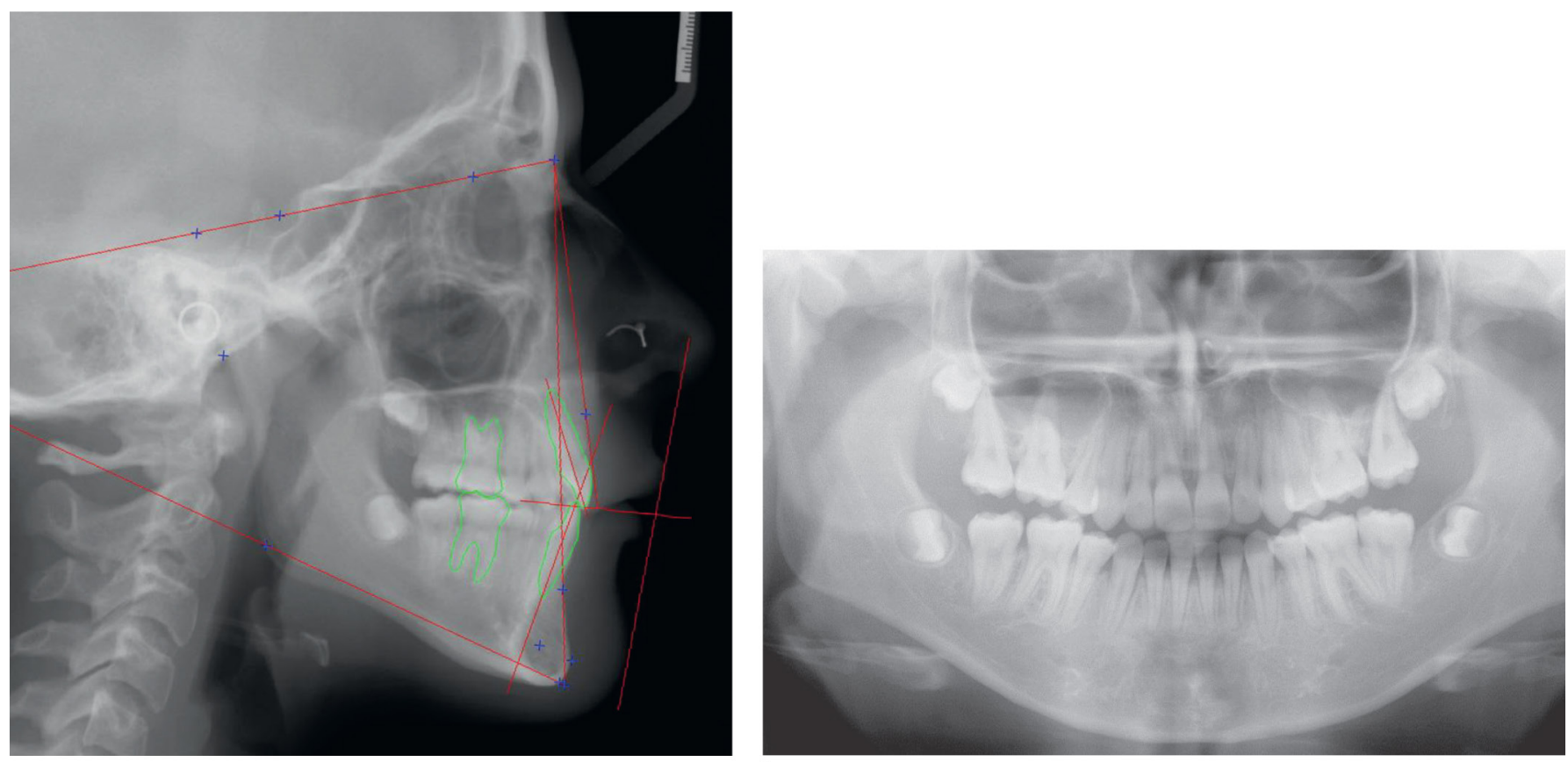

b

Figure 26

a, b: Teleradiograph with Steiner lines and panoramic view at end of treatment; Aug. 2014 (16yrs 11mo); ablation.

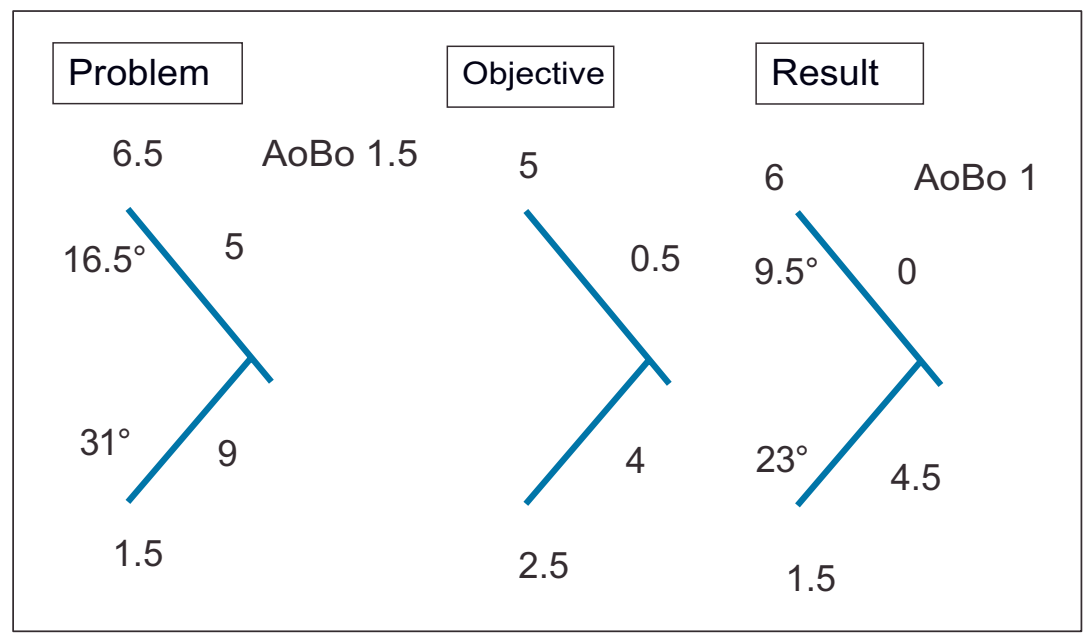

Figure 27

Check of anterior dentition. 
Table 1: Steiner analysis.

\begin{tabular}{|c|c|c|c|}
\hline \multicolumn{2}{|c|}{ Manon G. born Sept. 1997} & \multicolumn{2}{|c|}{ Steiner Cephalometry } \\
\hline Cephalometry & Norm & $\begin{array}{l}\text { May } 2011 \\
13 y \text { mo }\end{array}$ & $\begin{array}{l}\text { Aug } 14 \\
16 y 11 \mathrm{~m}\end{array}$ \\
\hline SNA & 2 & 85 & 85.5 \\
\hline SNB & 80 & 79 & 79.5 \\
\hline ANB & 2 & 6.5 & 6 \\
\hline SND & 76 & 75.5 & 77 \\
\hline 1/NAmm & 4 & 5 & 0 \\
\hline $1 / \mathrm{NA}^{\circ}$ & 22 & 16.5 & 9.5 \\
\hline $1 / \mathrm{NBmm}$ & 4 & 9 & 4.5 \\
\hline $1 / \mathrm{NB}^{\circ}$ & 25 & 31 & 21 \\
\hline Pog/NB & / & 1.5 & 1.5 \\
\hline $1 / 1$ & 131 & 126 & 143.5 \\
\hline Occl/ SN & 14 & 19 & 17.5 \\
\hline GoGn/SN & 32 & 34.5 & 36.5 \\
\hline SE & 51 & 49 & 43.5 \\
\hline SL & 22 & 20.5 & 18.5 \\
\hline
\end{tabular}

Table 2: Tweed analysis.

\begin{tabular}{|c|c|c|c|}
\hline \multicolumn{2}{|c|}{ Manon G. born Sept. 1997} & \multicolumn{2}{|c|}{ Tweed Cephalometry } \\
\hline Cephalometry & Norm & $\begin{array}{l}\text { May } 11 \\
13 y 8 m\end{array}$ & $\begin{array}{l}\text { Aug } 14 \\
16 y 11 \mathrm{~m}\end{array}$ \\
\hline
\end{tabular}

\begin{tabular}{|l|l|l|l|}
\hline FMIA & $27^{\circ}+/-3$ & 53.5 & 68.5 \\
FMA & $25^{\circ}+/-3$ & 31 & 29 \\
IMPA & $88^{\circ}+/-3$ & 95.5 & 82.5 \\
SNA & $82^{\circ}$ & 85 & 85.5 \\
SNB & $80^{\circ}$ & 79 & 79.5 \\
ANB & $2^{\circ}+/-2$ & 6.5 & 6 \\
AoBo & $2 \mathrm{~mm}+2$ & 1.5 & 1 \\
Occlusion plane & $10^{\circ}$ & 13 & 8 \\
Angle Z & $75+/-5$ & 61.5 & 75.5 \\
Upper lip & $/$ & 17.5 & 16.5 \\
Total chin & $/$ & 16 & 14.5 \\
Post facial height & $45 \mathrm{~mm}$ & 49 & 42.5 \\
Ant facial height & $65 \mathrm{~mm}$ & 71 & 66 \\
Post/Ant Index & 0,69 & 0.7 & 0.6 \\
Progression ratio & $2 / 1$ & & \\
\hline
\end{tabular}




\section{CASE 2}

\section{Diagnosis}

Carol T., born January 1995, consulted in February 2007, aged 12 years 1 month.

Facial examination found class III with notable cheek-bone aplasia (fig. 28) .
Intra-oral examination confirmed this impression, with slight molar class III, despite overjet in 11-21, due to crowding (fig. 29). Cephalometry (figs 31 and 32) confirmed slight hyperdivergent

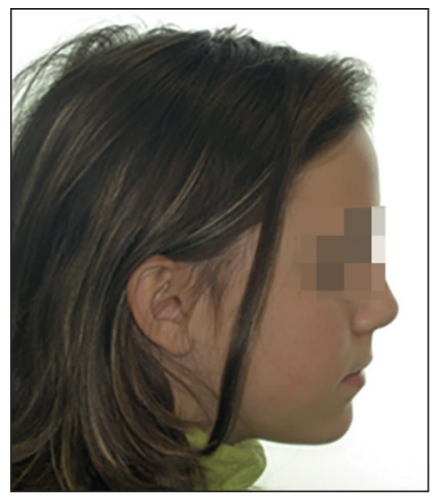

a

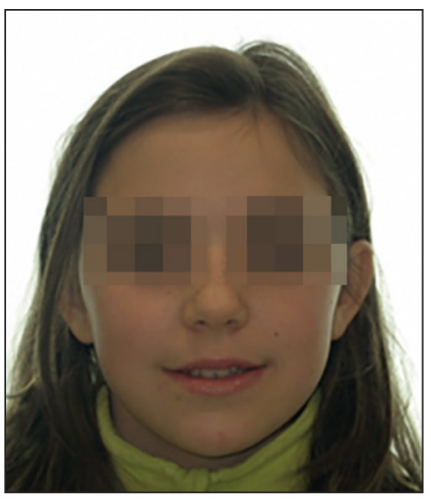

Figure 28

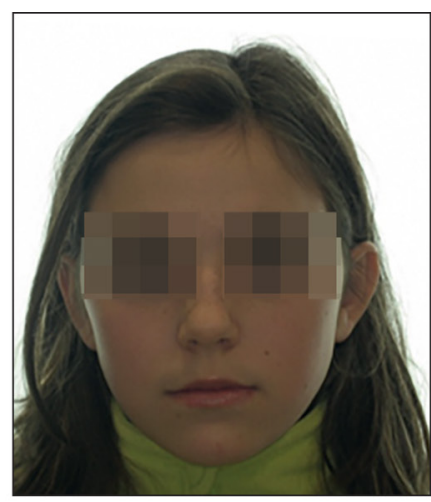

b

a, b, c: Lateral, smile and frontal views. $1^{\text {st }}$ documents. Dec. $2007(12 y 11 \mathrm{~m})$.

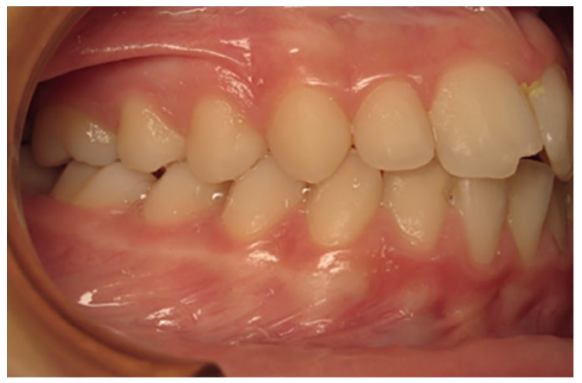

a

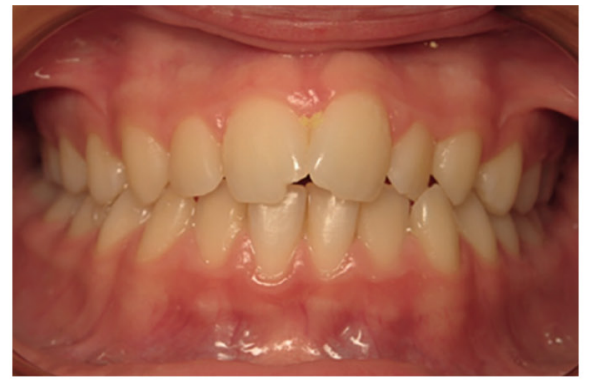

Figure 29

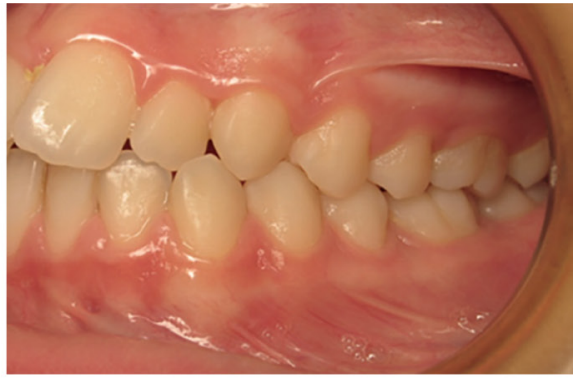

C

a, b, c: Right, frontal and left vestibular views. $1^{\text {st }}$ documents. Dec. 2007 (12y 11m).

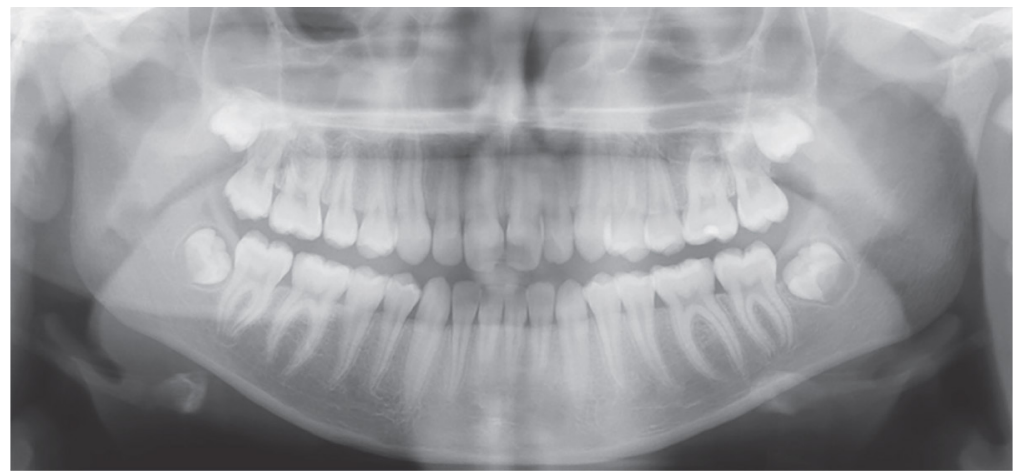

Figure 30

Panoramic view. $1^{\text {st }}$ documents. Dec. 2007 (12y 11m). 
class III and strong bilabioversion, reducing, as is often the case, the sensation of slight skeletal dysmorphism and "saving" the class III.

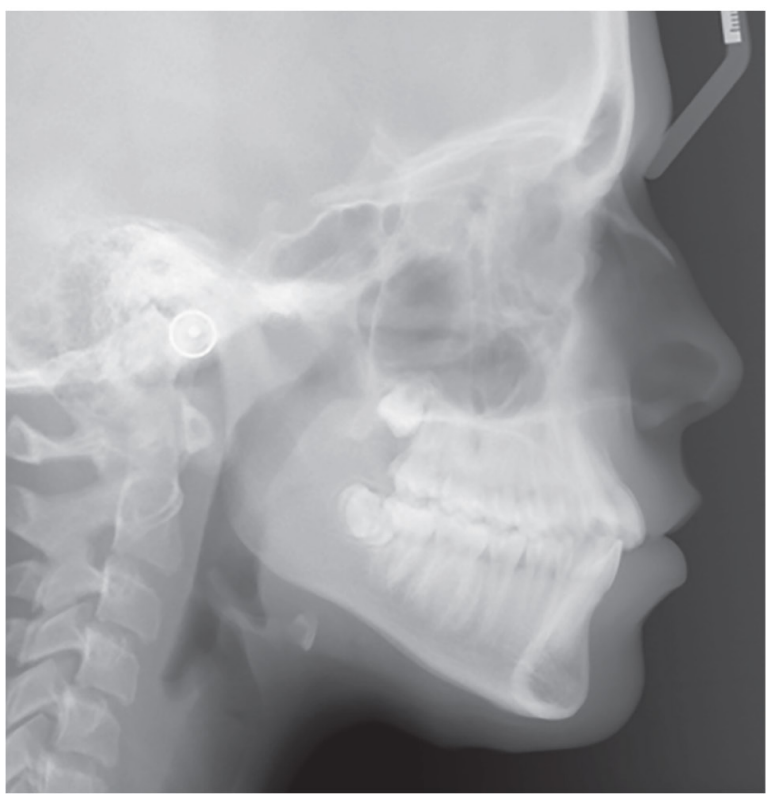

Bilabioversion was stronger in the maxilla than mandible, due to class III compensations superimposed on the bilabioversion.

\begin{tabular}{l|c|cc}
\hline \multicolumn{4}{|c}{ Analyse de Tweed: } \\
\hline & & & \\
\hline Angle FMA & $25.00^{\circ}$ & 28.01 & {$[+3.01]$} \\
\hline Angle FMIA & $68.00^{\circ}$ & 55.59 & {$[-12.41]$} \\
\hline Angle IMPA & $87.00^{\circ}$ & 96.40 & {$[+9.40]$} \\
\hline & & & \\
\hline Angle SNA & $82.00^{\circ}$ & 79.54 & {$[-2.46]$} \\
\hline Angle SNB & $80.00^{\circ}$ & 77.96 & {$[-2.04]$} \\
\hline Angle ANB & $2.00^{\circ}$ & 1.58 & {$[-0.42]$} \\
\hline A0-BO & $0.00 \mathrm{~mm}$ & -4.67 & {$[-4.67]$} \\
\hline Occlusal-SN & $14.00^{\circ}$ & 21.10 & {$[+7.10]$} \\
\hline Occlusal-FH & $10.00^{\circ}$ & 12.59 & {$[+2.59]$} \\
\hline Inter-incisif & $135.00^{\circ}$ & 110.42 & {$[-24.58]$} \\
\hline total chin & $11.00 \mathrm{~mm}$ & 13.74 & {$[+2.74]$} \\
\hline upper lip & $13.00 \mathrm{~mm}$ & 13.56 & {$[+0.56]$} \\
\hline Angle Z & $78.00^{\circ}$ & 70.46 & {$[-7.54]$} \\
\hline Nasion-ENA & $0.00 \mathrm{~mm}$ & 51.76 & {$[+51.76]$} \\
\hline Menton-ENA & $65.68 \mathrm{~mm}$ & 71.21 & {$[+5.53]$} \\
\hline HFP & $45.00 \mathrm{~mm}$ & 42.37 & {$[-2.63]$} \\
\hline HFA & $65.00 \mathrm{~mm}$ & 69.44 & {$[+4.44]$} \\
\hline HFP / HFA & 0.70 & 0.61 & {$[-0.09]$} \\
\hline b & & & \\
\hline
\end{tabular}

Figure 31

a and b: Teleradiography and Tweed cephalometry. $1^{\text {st }}$ documents. Dec. 2007 (12y 11m). Tweed analysis

Inter-incisor

Chin

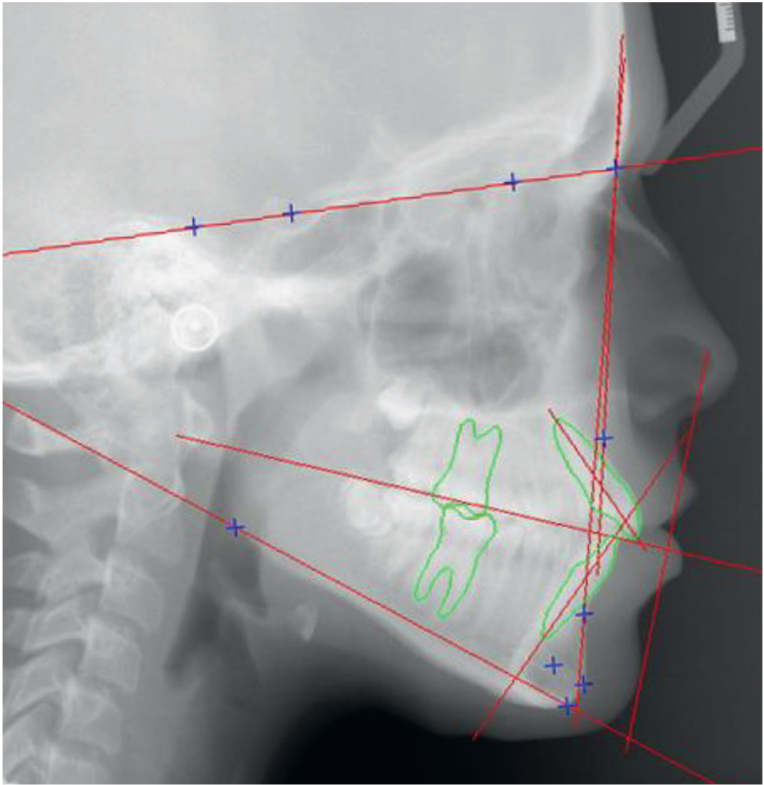

\begin{tabular}{|c|c|c|c|}
\hline \multicolumn{4}{|c|}{ Analyse de Steiner : } \\
\hline SNA & $82.00^{\circ}$ & 79.54 & {$[-2.46]$} \\
\hline SNB & $80.00^{\circ}$ & 77.96 & {$[-2.04]$} \\
\hline ANB & $2.00^{\circ}$ & 1.58 & {$[-0.42]$} \\
\hline SND & $76.00^{\circ}$ & 74.84 & {$[-1.16]$} \\
\hline $\mathrm{SL}$ & $51.00 \mathrm{~mm}$ & 51.00 & {$[0.00\}$} \\
\hline SE & $22.00 \mathrm{~mm}$ & 22.36 & {$[+0.36]$} \\
\hline GoGn to SN & $32.00^{\circ}$ & 36.17 & {$[+4.17]$} \\
\hline I to NA mm & $4.00 \mathrm{~mm}$ & 8.46 & {$[+4.46]$} \\
\hline $\mathrm{i}$ to $\mathrm{NB} \mathrm{mm}$ & $4.00 \mathrm{~mm}$ & 5.90 & {$[+1.90]$} \\
\hline Pog to NB & $0.00 \mathrm{~mm}$ & 0.90 & {$[+0.90]$} \\
\hline Pog to i.NB & $0.00 \mathrm{~mm}$ & 5.00 & {$[+5.00]$} \\
\hline I to NA. & $22.00^{\circ}$ & 37.10 & {$[+15.10]$} \\
\hline i to NB* & $25.00^{\circ}$ & 30.89 & {$[+5.89]$} \\
\hline I to $\mathrm{i}^{\circ}$ & $131.00^{\circ}$ & 110.42 & {$[-20.58)$} \\
\hline $0 \mathrm{ccl}$ to SN & $14.00^{\circ}$ & 21.10 & {$[+7.10]$} \\
\hline
\end{tabular}

b

Figure 32

a and b: Teleradiography with Steiner lines, and Steiner cephalometry. $1^{\text {st }}$ documents. Dec. 2007 (12y 11m). Steiner analysis. 


\section{Treatment plan}

Space calculations were very negative in the anterior (fig. 33) and posterior sectors (fig. 34), and extraction of the 4 first premolars and 4 third molars was inevitable (figs 30-34). Sacrificing the premolars enabled an anterior strategy free of compromise, with rigorous anchorage (fig. 32).

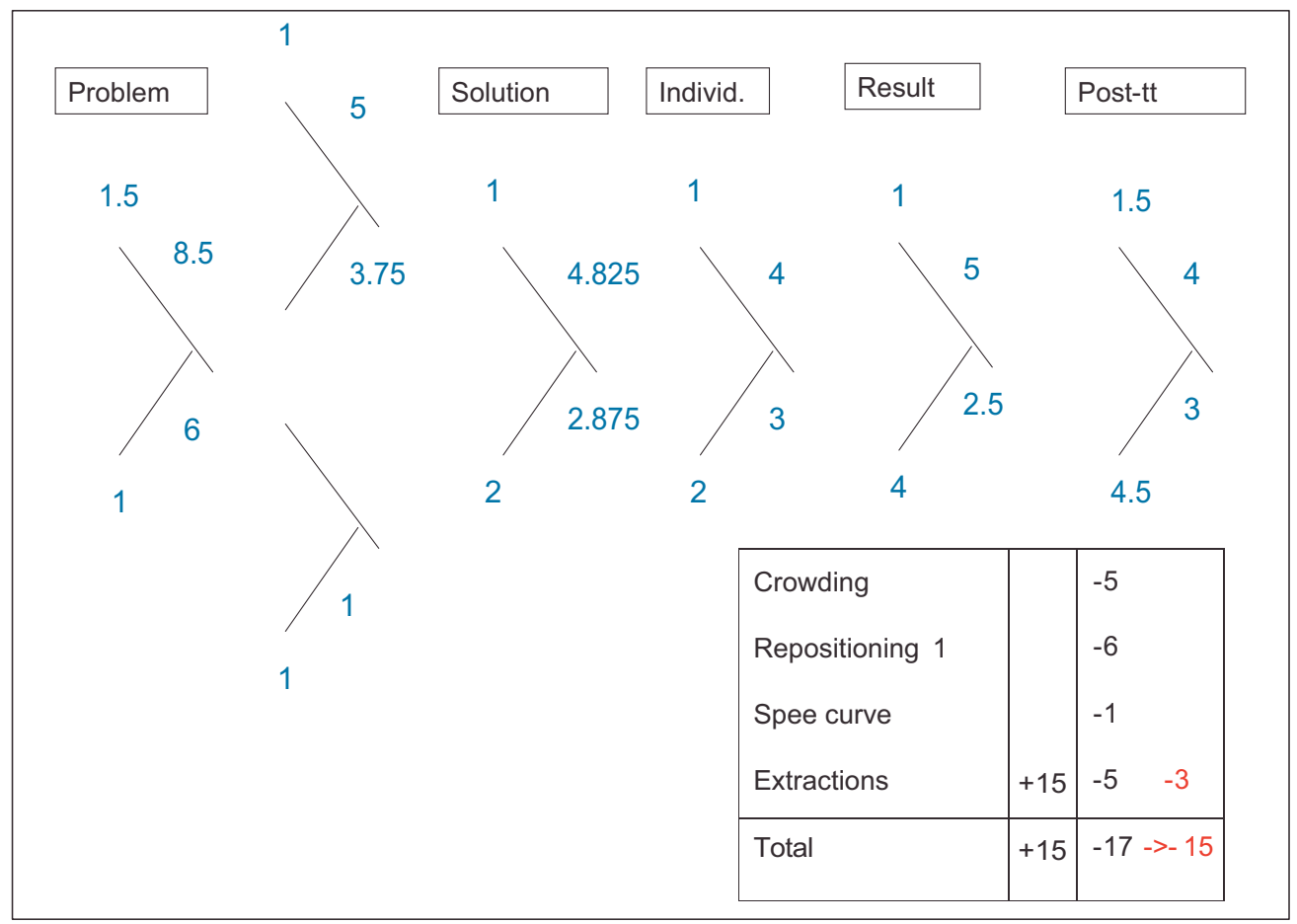

Figure 33

Steiner chevrons and anterior "box."

Posterior space

Free space (TMD)

Distal $37-47$ :

38-48

$-6$

Expected anchorage loss

Posterior growth, girl*

$+3$

Expected free space at $18 \mathrm{yrs}$

$-15$

No hope of "salvaging" $4 \times 8$ s

*posterior growth calculated as: $Y=33.034$ -

1.722xage

Tweed calculation gave post. growth $=3 \mathrm{~mm}$

Figure 34

Posterior space "box". 
Multibracket treatment and finishing (March 2008 (13y 2m) Oct. 2010 (15y 9m)

Straight arch attachments with Roth prescription and $-10^{\circ}$ and $-15^{\circ}$ built-in tip-back on mandibular molars improved anchorage (passive selfligating brackets).

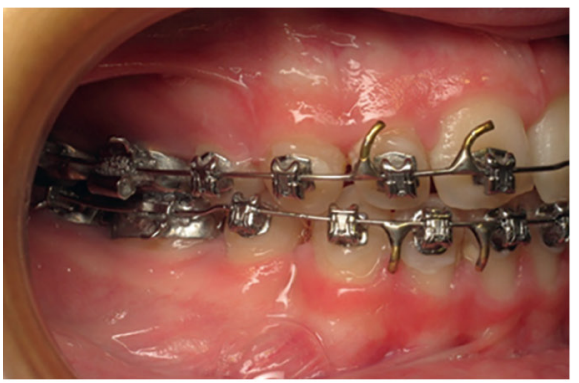

a

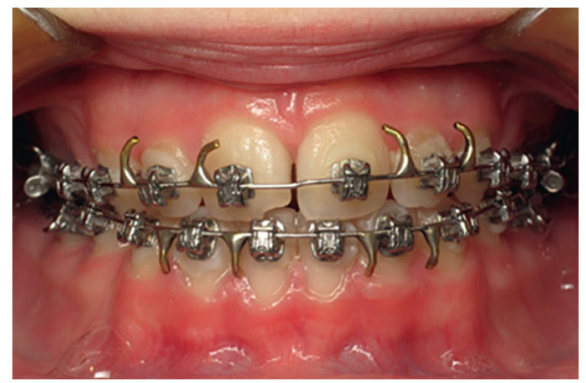

b
Intercuspation finishing was of course rigorous. The terminal arch (fig. 35-38) comprised mainly $2^{\text {nd }}$ order shaping (steps, accentuated maxillary and inversed mandibular Spee curve, tip-back on 11, etc.), but also $1^{\text {st }}$ order (fig. 36b) and even $3^{\text {rd }}$ order (fig. 37a and c, and fig. 45).

Figure 35

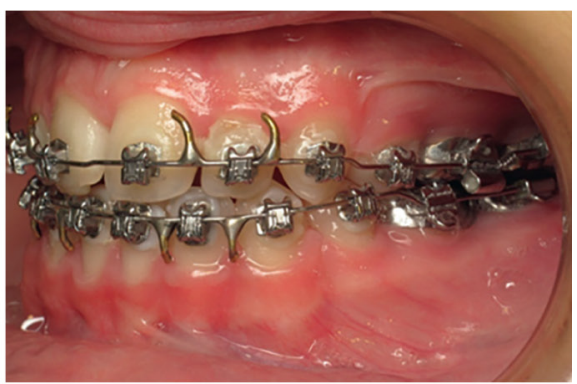

C

a, b, c: Right, frontal and left vestibular views. Finishing: Aug. 2010, 15y 7m.

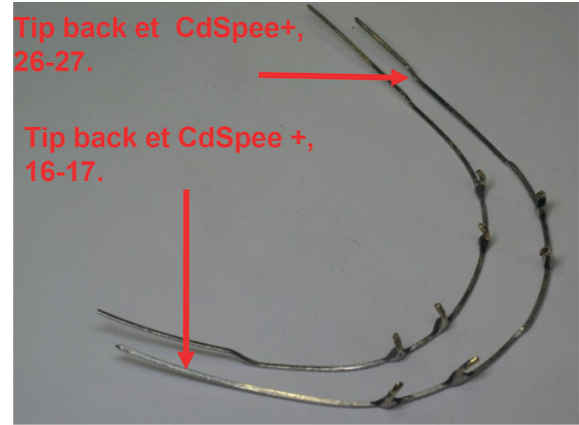

a

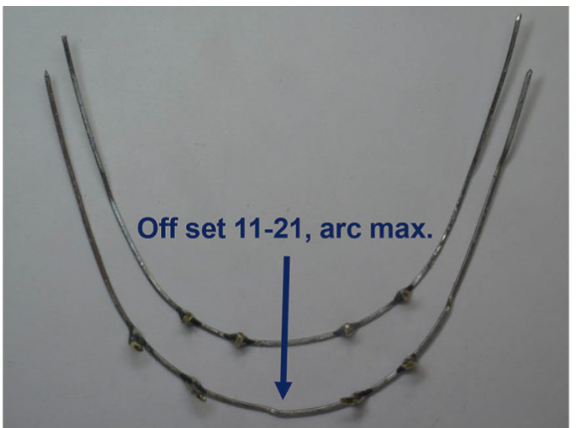

b

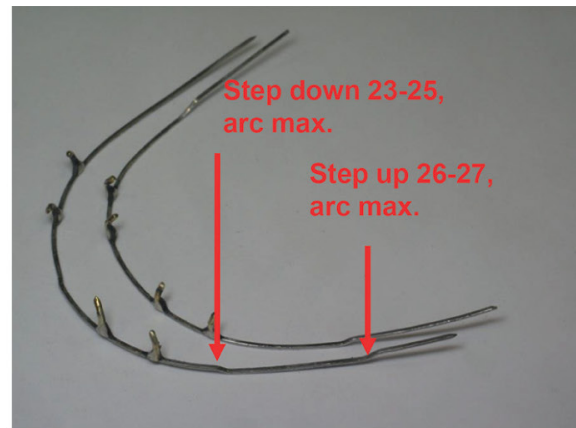

C

Figure 36

a, b, c: Right frontal and left view, maxillary arch: Finishing: Aug. 2010, 15y $7 \mathrm{~m}$.

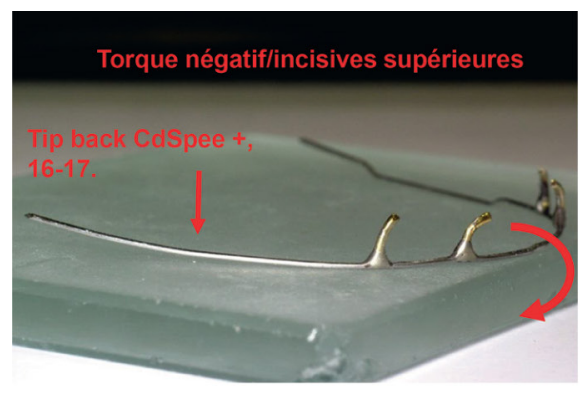

a

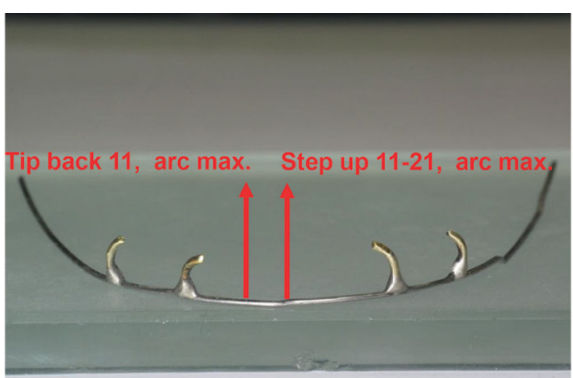

b

Figure 37

$a, b, c::$ Right frontal and left view, maxillary arch. Finishing: detail of $2^{\text {nd }}$ order control: Aug. 2010, 15y 7m. 
Ablation documents (figs 39-45) confirmed precise static occlusion adjustment.

Finishing comprised class III overdecompensation, especially maxillary, where linear and particularly angular protrusion was very strong (torque over-correction), to counter possible slight late type-C relapse (figs 44-46).

Third molars were extracted (fig. 48), as planned since the outset in September 2011 (fig. 34).

Post-treatment stability was excellent (figs 47 and 48).

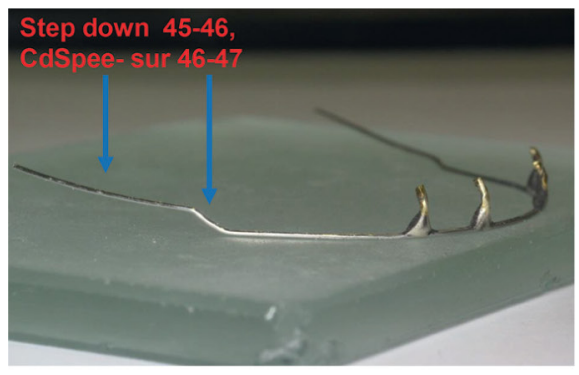

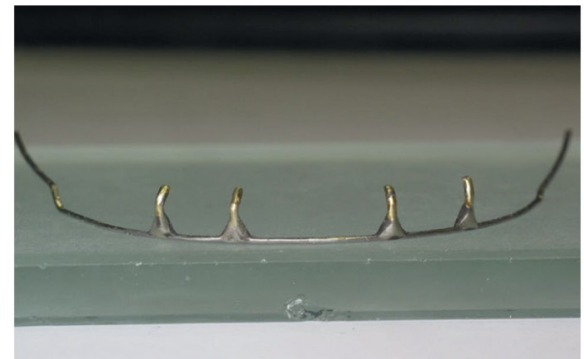

Figure 38

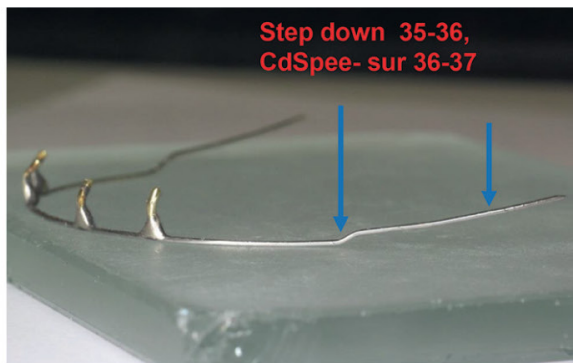

C

a, b, c: Mandibular arch, right, frontal and left views: Finishing: Aug. 2010, 15y 7m Inverted Spee curve on 46-47 / Inverted Spee curve on 36-37

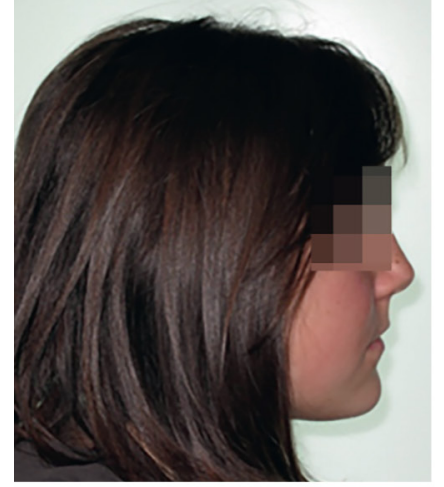

a

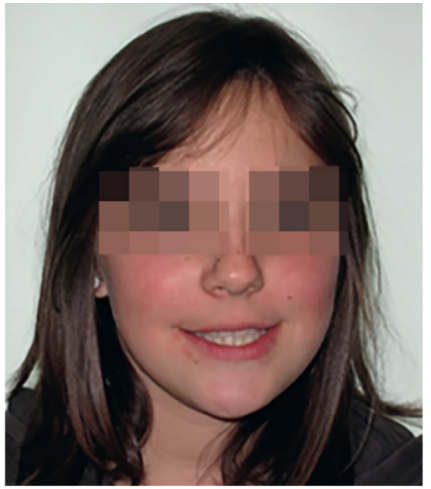

Figure 39

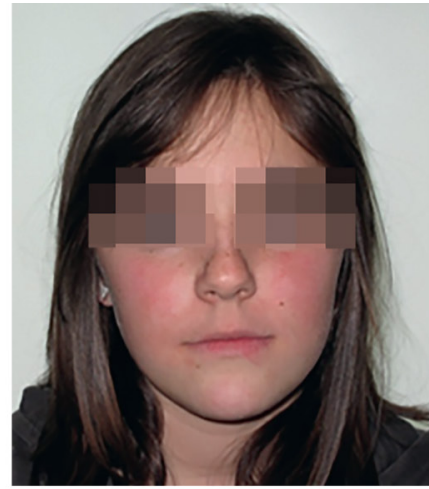

C

a, b, c: Lateral, smile and frontal views; ablation, Oct. 2010, $15 \mathrm{y} 9 \mathrm{~m}$.

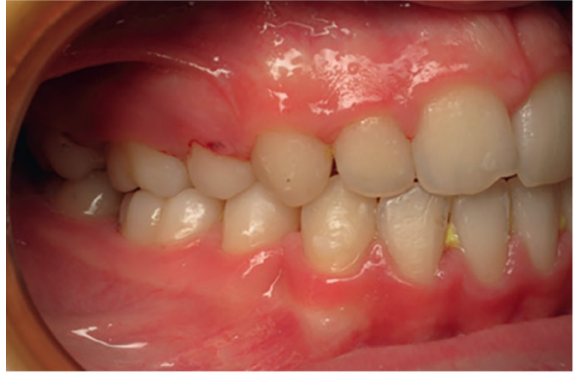

a

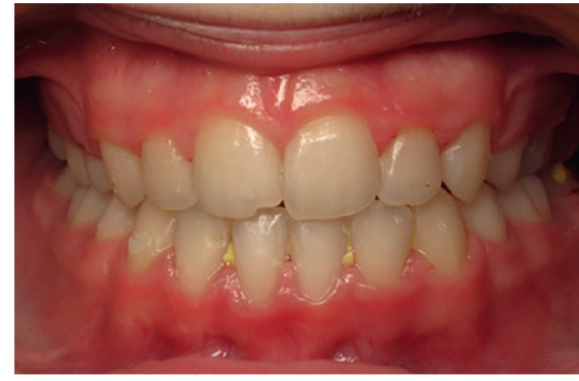

Figure 40

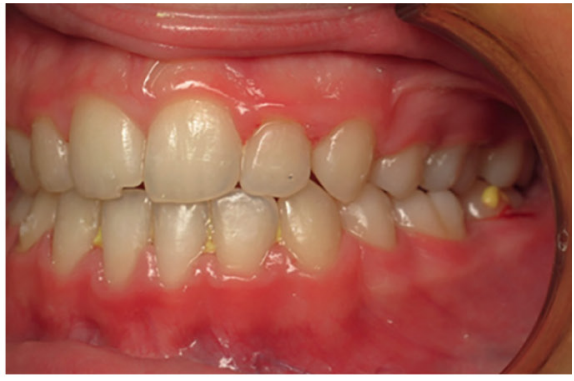

C

a, b, c: Right, frontal and left vestibular views; ablation, Oct. 2010, 15y 9m. 


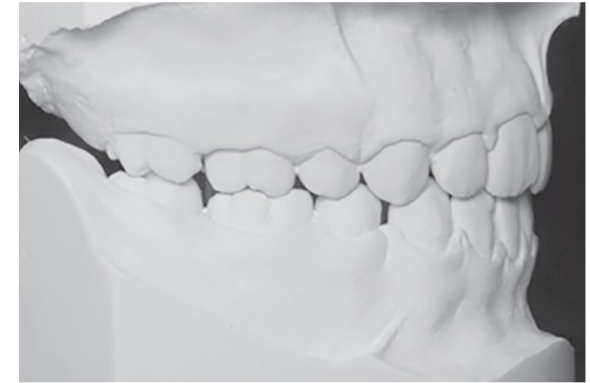

a

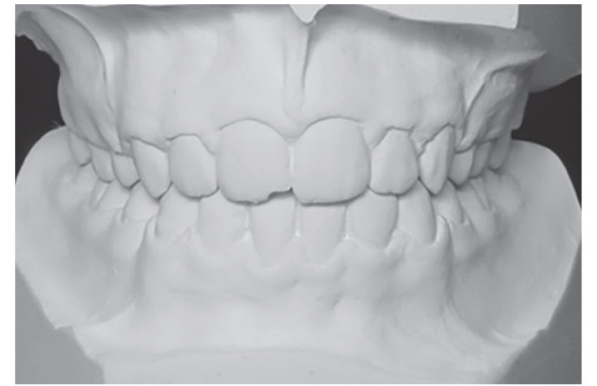

b

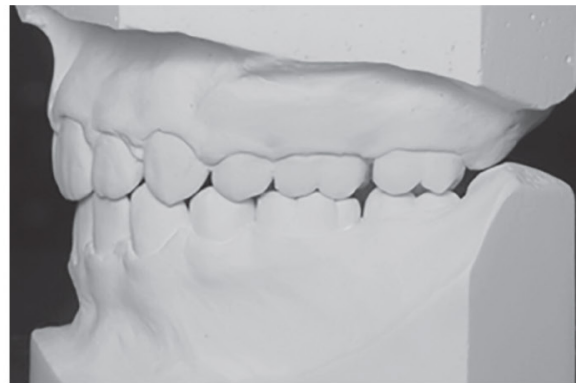

C

Figure 41

a, b, c: Molds: Right, frontal and left vestibular views: ablation, Oct. 2010, 15y 9m.

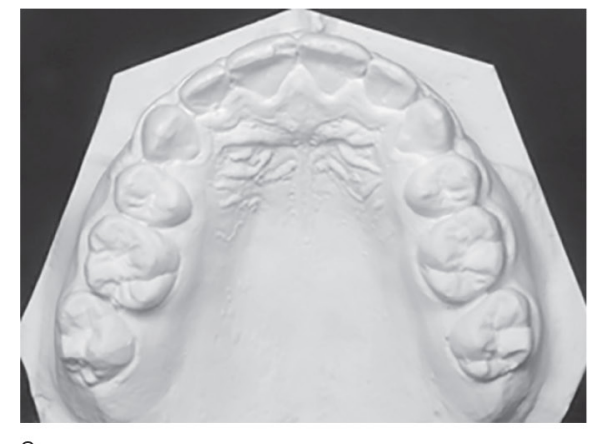

a

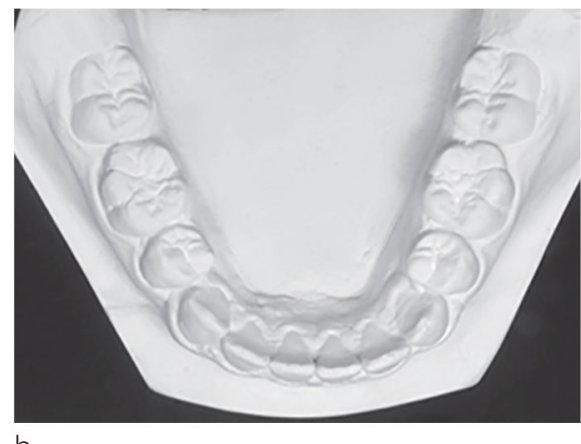

b

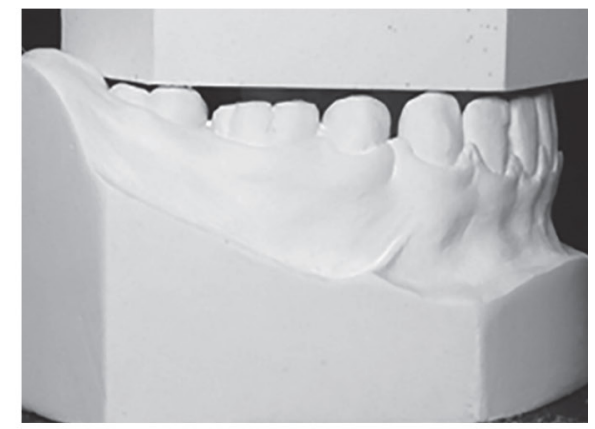

C

Figure 42

a, b, c: Molds: occlusal, maxillary and mandibular (with Spee curve) views; ablation, Oct. 2010, 15y 9m.

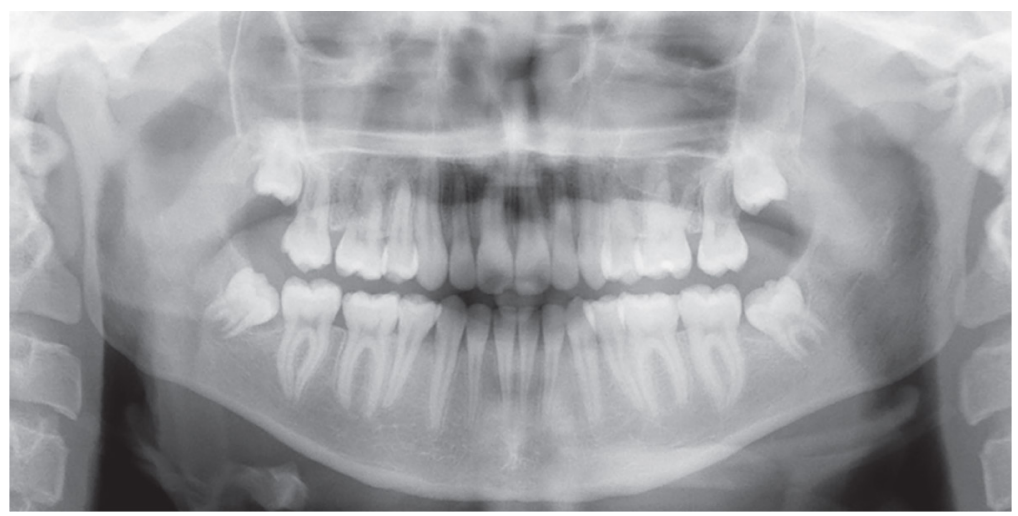

Figure 43

Panoramic end of treatment view; ablation, Oct. 2010, 15y 9m. 


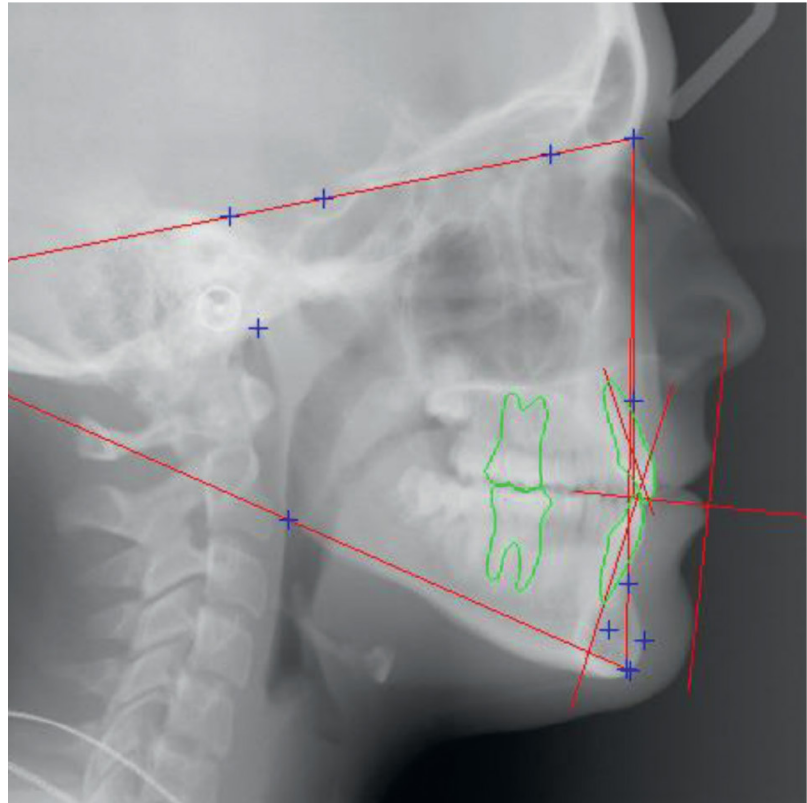

a

\begin{tabular}{|c|c|c|c|}
\hline SNA. & 82. $0^{\circ}$ & 79.0 & -1.0 \\
\hline SNB & $80.0^{\circ}$ & 78.3 & OK \\
\hline ANB & 2. $0^{\circ}$ & 0.8 & OK \\
\hline SND & $76.0^{\circ}$ & 76.1 & OK \\
\hline$S L$ & $51.0 \mathrm{~mm}$ & 55.0 & 1. 0 \\
\hline SE & 22. $0 \mathrm{~mm}$ & 22.6 & OK \\
\hline GoGn to SN & 32. $0^{\circ}$ & 34.8 & 0.8 \\
\hline I to NA mm & 4. $0 \mathrm{~mm}$ & 4. 8 & OK \\
\hline $\mathrm{i}$ to $\mathrm{NB} \mathrm{mm}$ & 4. $0 \mathrm{~mm}$ & 2.5 & OK \\
\hline Pog to NB & $0.0 \mathrm{~mm}$ & 3. 8 & OK \\
\hline Pog to $i-N B$ & 0. $0 \mathrm{~mm}$ & -1.3 & OK \\
\hline I to NA ० & 22. $0^{\circ}$ & 18. 3 & -1.7 \\
\hline i to NB o & 25. $0^{\circ}$ & 16.7 & -6.3 \\
\hline I to $i^{\circ}$ & 131. $0^{\circ}$ & 144.2 & 11.2 \\
\hline Occl to $\mathrm{SN}$ & $14.0^{\circ}$ & 17.1 & 1. 1 \\
\hline
\end{tabular}

b

Figure 44

a, b: Teleradiograph with Steiner lines and end-of-treatment cephalometry; ablation, Oct. 2010, 15y 9m.

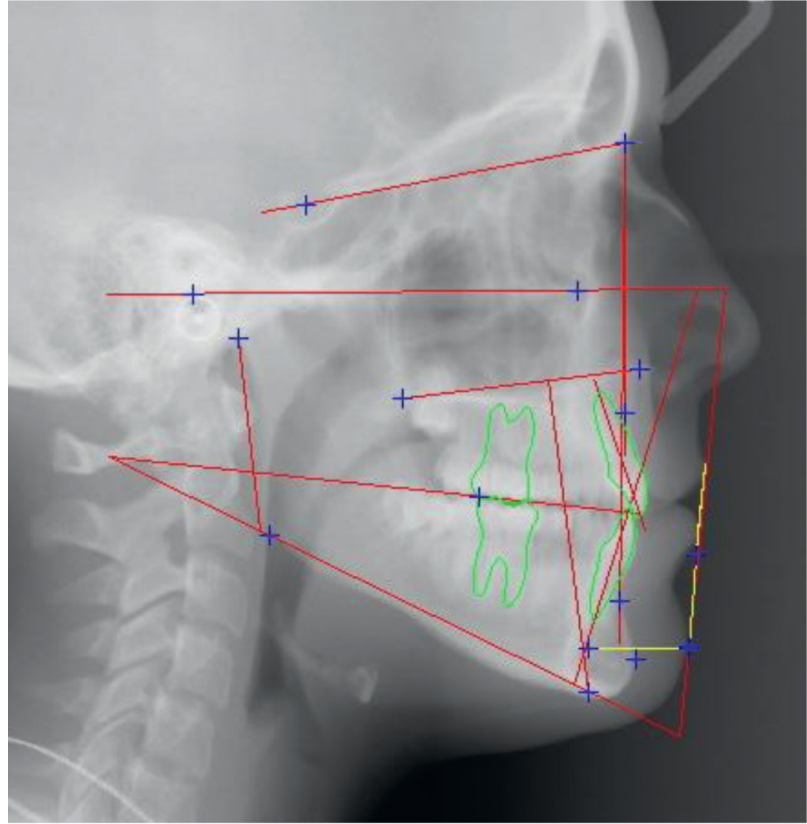

a

\begin{tabular}{lcrc}
\multicolumn{5}{c}{ Analyse de Tweed : } \\
Angle FMA & $25.0^{\circ}$ & 26.6 & \multicolumn{1}{c}{ OK } \\
Angle FMIA & $68.0^{\circ}$ & 72.0 & 1.0 \\
Angle IMPA & $87.0^{\circ}$ & 81.5 & -0.5 \\
& & & \\
Angle SNA & $82.0^{\circ}$ & 79.0 & -1.0 \\
Angle SNB & $80.0^{\circ}$ & 78.3 & OK \\
Angle ANB & $2.0^{\circ}$ & 0.8 & OK \\
AO-BO & $0.0 \mathrm{~mm}$ & -3.2 & -1.2 \\
\hline Occlusal - SN & $14.0^{\circ}$ & 17.1 & 1.1 \\
Occlusal - FH & $10.0^{\circ}$ & 6.6 & -1.4 \\
Inter-incisif & $135.0^{\circ}$ & 144.2 & 6.2 \\
total chin & $11.0 \mathrm{~mm}$ & 16.2 & 0.2 \\
upper lip & $13.0 \mathrm{~mm}$ & 13.0 & OK \\
Angle Z & $78.0^{\circ}$ & 83.8 & 2.8 \\
Nasion - ENA & $56.6 \mathrm{~mm}$ & 51.8 & OK \\
Menton - ENA & $65.7 \mathrm{~mm}$ & 75.3 & OK \\
HFP & $45.0 \mathrm{~mm}$ & 44.7 & OK \\
HFA & $65.0 \mathrm{~mm}$ & 72.6 & OK \\
\hline HFP / HFA & 0.7 & 0.6 & OK \\
\hline DFA & & &
\end{tabular}

Figure 45

a, b: Teleradiograph with Tweed lines and end-of-treatment cephalometry; ablation, Oct. 2010, 15y 9m. Tweed analysis

Interincisor

Chin 


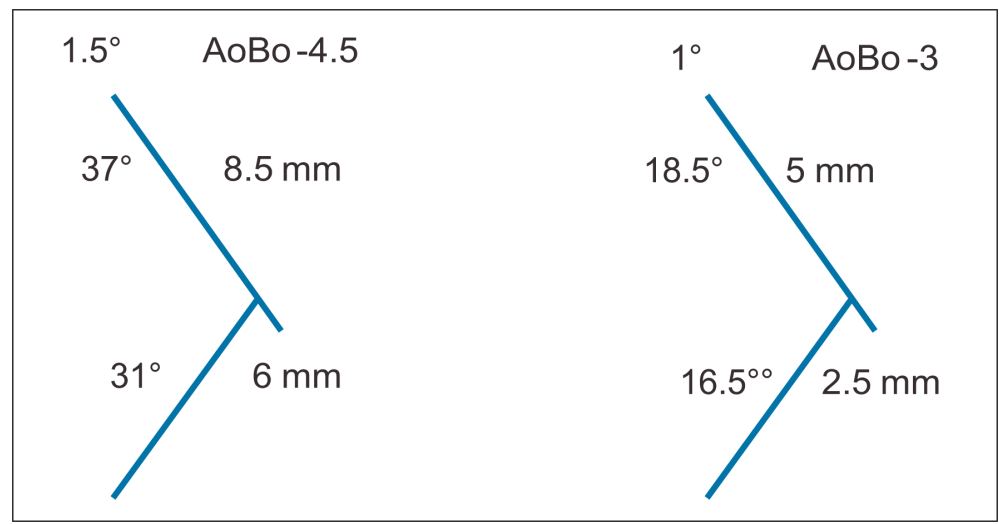

Figure 46

Control of anterior dentition.

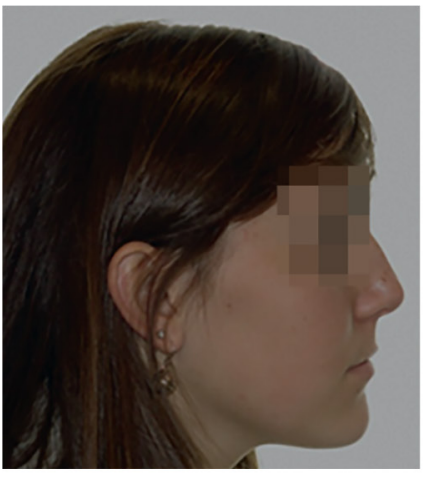

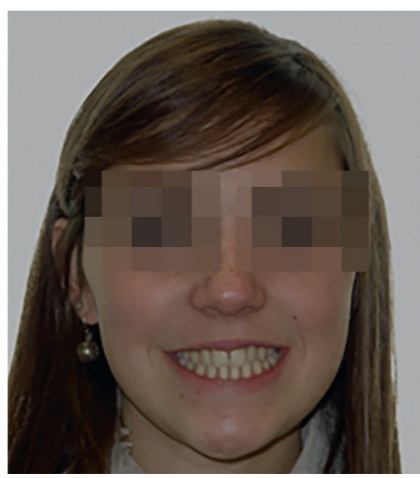

Figure 47

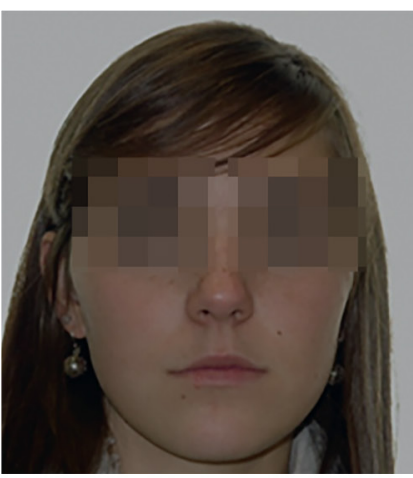

$\mathrm{C}$

a, b, c: Lateral, smile and frontal views: 3 years post-treatment: Oct. 2013, 18y 9m.

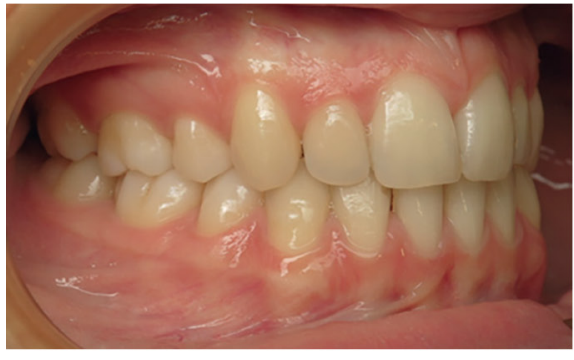

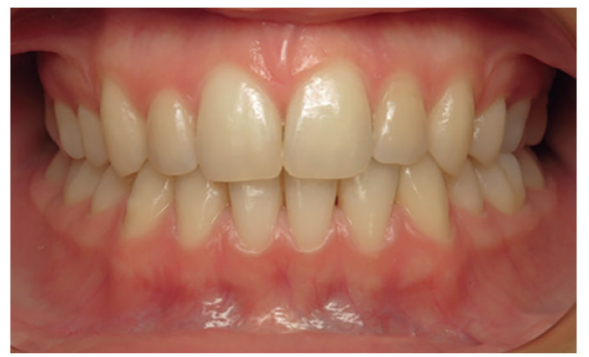

Figure 48

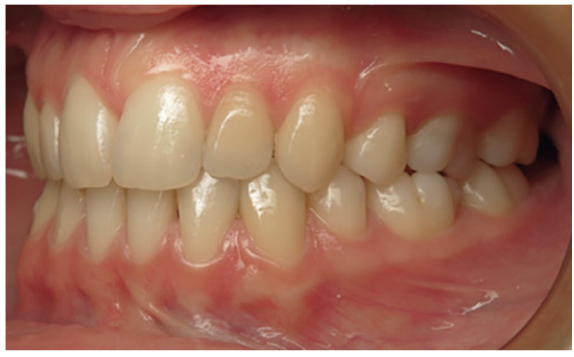

C

a, b, c: Right, frontal and left vestibular intra-oral views: 3 years post-treatment: Oct. 2013, 18y 9m.

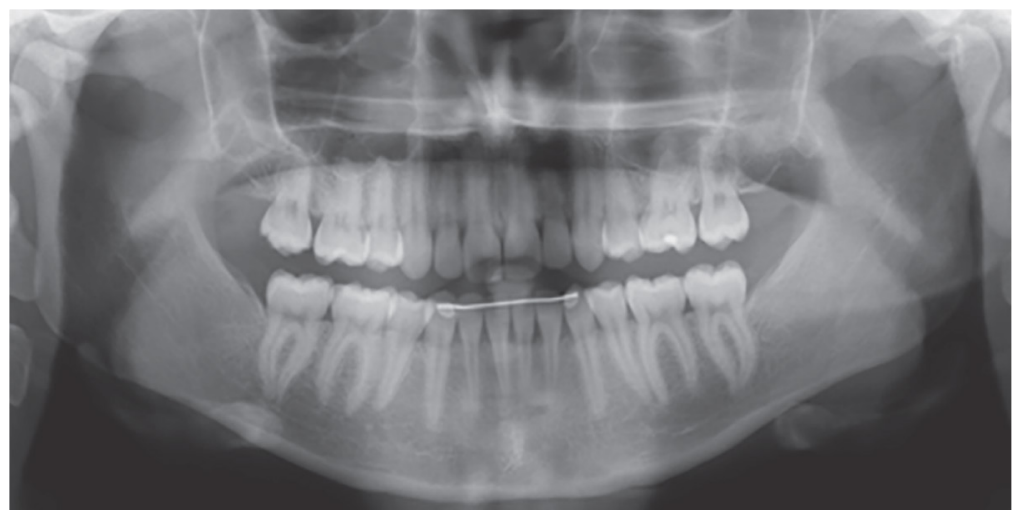

Figure 49

Panoramic view after extraction of 18-28-38-48. 3 years post-treatment: Oct. 2013, 18y 9m. 


\section{CASE 3}

\section{Diagnosis}

Audrey, born January 1998, consulted in May 2011, aged 13 years 4 months. Above all, her smile was impaired by crowding in both arcades (figs 50 and 51). Facial examination found vertical excess and difficult labial contact. Teleradiography confirmed insufficient occlusal contact, with slight anterior gap; cephalometry found hyperdivergent class I (figs 53 and 54).

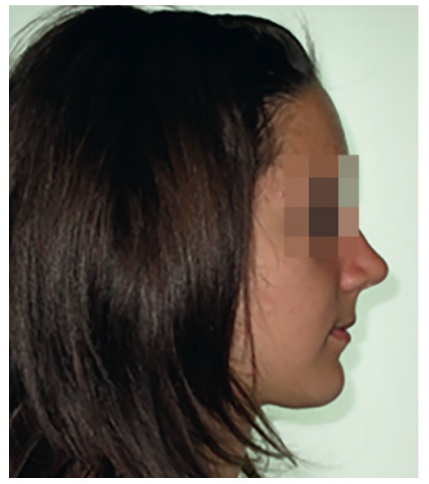

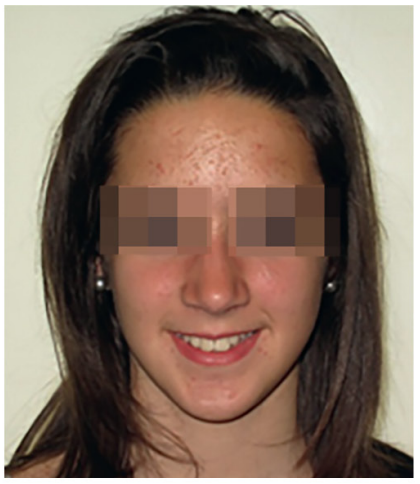

Figure 50

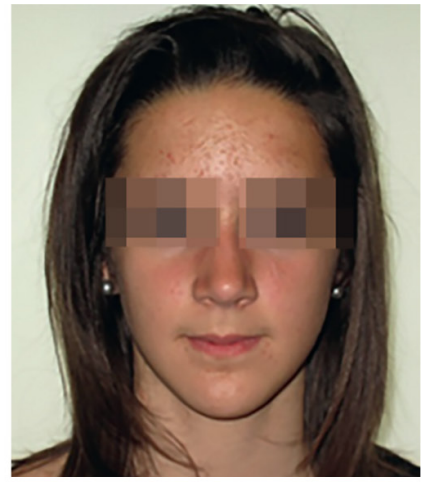

a, b, c: Lateral, smile and frontal views. $1^{\text {st }}$ documents, May 2011 (13y 4m).

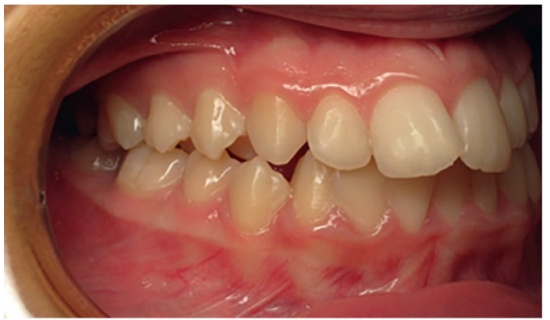

a

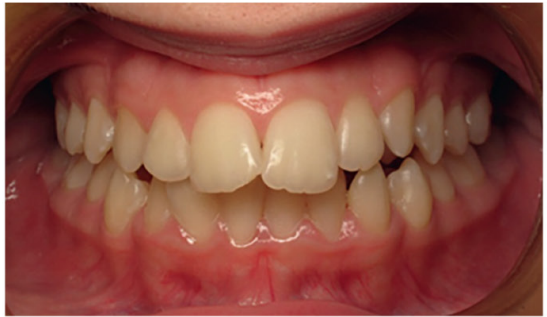

b

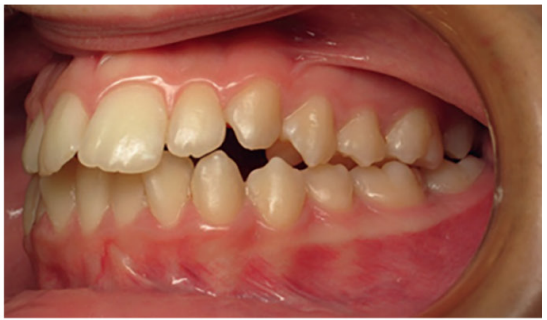

C

Figure 51

a, b, c: Right, frontal and left intra-oral views. $1^{\text {st }}$ documents, May 2011 (13y 4m).

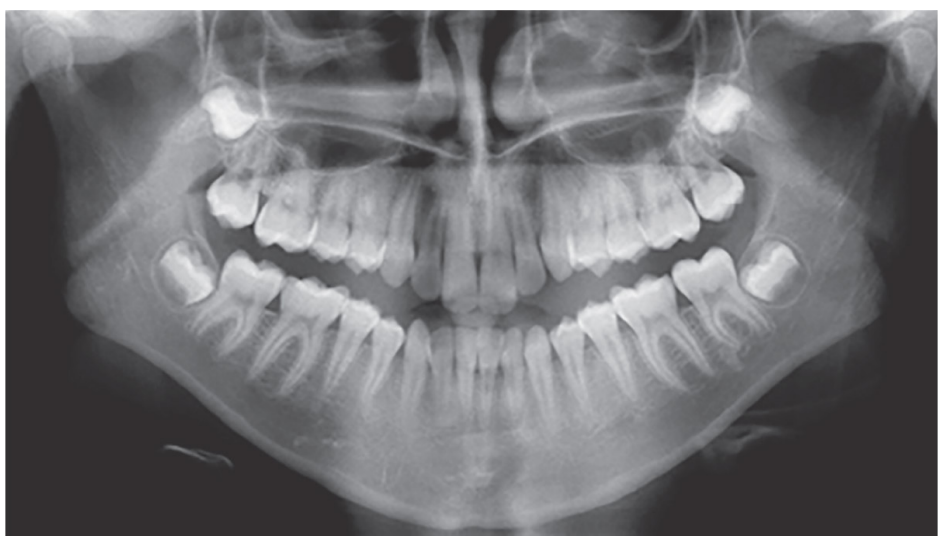

Figure 52

Panoramic view. $1^{\text {st }}$ documents, May 2011 (13y 4m) 
Intra-oral examination found superior protrusion with overjet, confirmed on cephalometry (figs 53 and 54).

Posterior DMD was moderate (figs 52 and 56).

\section{Treatment plan}

An anterior alignment-advancement plan was abandoned, mainly due to the vertical problem: anterior balance would have been precarious.

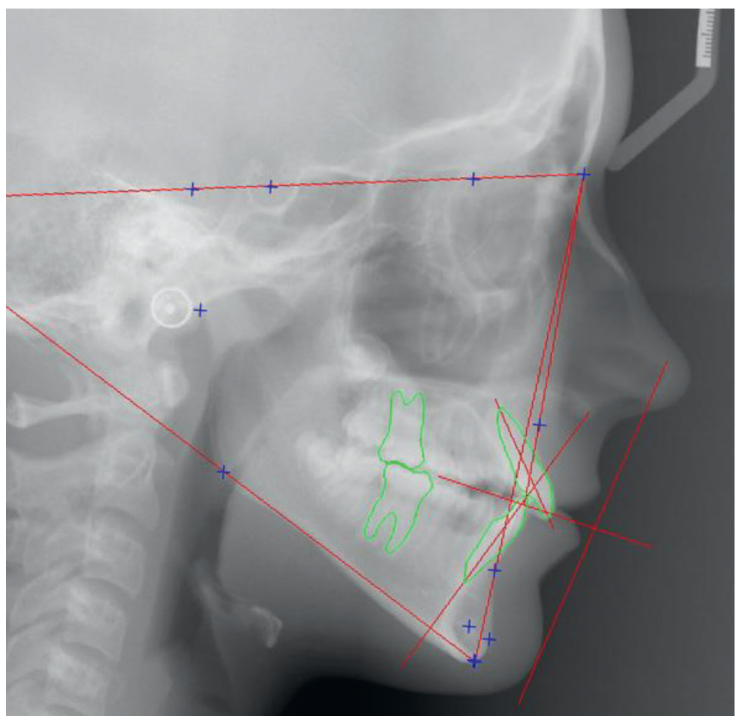

a

\begin{tabular}{l|c|r|c|}
\hline SNA & $82.0^{\circ}$ & 77.8 & -2.2 \\
\hline SNB & $80.0^{\circ}$ & 75.2 & -2.8 \\
\hline ANB & $2.0^{\circ}$ & 2.5 & OK \\
\hline SND & $76.0^{\circ}$ & 73.7 & -0.3 \\
\hline SL & $51.0 \mathrm{~mm}$ & 52.4 & OK \\
\hline SE & $22.0 \mathrm{~mm}$ & 20.0 & OK \\
\hline GoGn to SN & $32.0^{\circ}$ & 39.2 & 5.2 \\
\hline I to NA mm & $4.0 \mathrm{~mm}$ & 7.6 & 1.6 \\
\hline i to NB mm & $4.0 \mathrm{~mm}$ & 4.7 & OK \\
\hline Pog to NB & $0.0 \mathrm{~mm}$ & 2.5 & OK \\
\hline Pog to i-NB & $0.0 \mathrm{~mm}$ & 2.2 & OK \\
\hline I to NA ${ }^{\circ}$ & $22.0^{\circ}$ & 34.1 & 10.1 \\
\hline i to NB $\circ$ & $25.0^{\circ}$ & 23.7 & OK \\
\hline I to i & $131.0^{\circ}$ & 119.7 & -9.3 \\
Occl to SN & $14.0^{\circ}$ & 20.2 & 4.2
\end{tabular}

Figure 53

a and b: Lateral teleradiograph with Steiner lines and Steiner cephalometry. 1st documents, May 2011 (13y 4m).

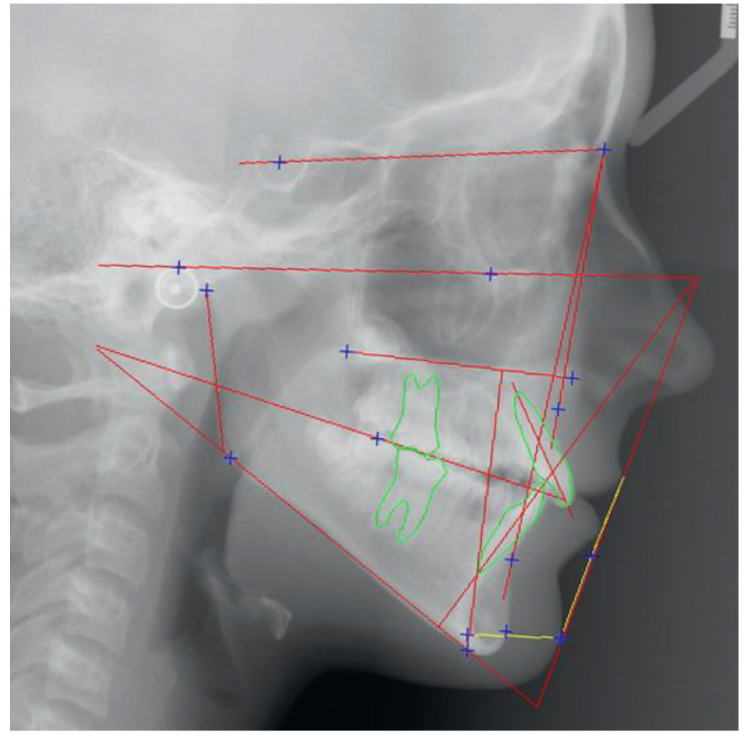

a

\begin{tabular}{|c|c|c|c|}
\hline & Analyse de Tweed & : & \\
\hline Angle FMA & 25. $0^{\circ}$ & 38. 1 & 8. 1 \\
\hline Angle FMIA & $68.0^{\circ}$ & 54.8 & -10.2 \\
\hline Angle IMPA & $87.0^{\circ}$ & 87.1 & OK \\
\hline Angle SNA & 82. $0^{\circ}$ & 77.8 & -2.2 \\
\hline Angle SNB & $80.0^{\circ}$ & 75.2 & -2.8 \\
\hline Angle ANB & 2. $0^{\circ}$ & 2. 5 & OK \\
\hline $\mathrm{AO}-\mathrm{BO}$ & $0.0 \mathrm{~mm}$ & -0.8 & OK \\
\hline Occlusal - SN & $14.0^{\circ}$ & 20.2 & 4. 2 \\
\hline Occlusal - FH & $10.0^{\circ}$ & 17. 0 & 5. 0 \\
\hline Inter-incisif & $135.0^{\circ}$ & 119.7 & -12.3 \\
\hline total chin & 11. $0 \mathrm{~mm}$ & 16.6 & 0.6 \\
\hline upper lip & 13. $0 \mathrm{~mm}$ & 12.7 & OK \\
\hline Angle $z$ & $78.0^{\circ}$ & 70.6 & -4.4 \\
\hline Nasion - ENA & $54.9 \mathrm{~mm}$ & 57,1 & OK \\
\hline Menton - ENA & $65.7 \mathrm{~mm}$ & 72.2 & OK \\
\hline HFP & 45. $0 \mathrm{~mm}$ & 40.5 & OK \\
\hline HFA & 65. $0 \mathrm{~mm}$ & 70.5 & OK \\
\hline $\mathrm{HFP} / \mathrm{HFA}$ & 0.7 & 0.6 & OK \\
\hline
\end{tabular}

Figure 54

a and b: Lateral teleradiograph with Tweed lines and Tweed cephalometry. 1st documents, May 2011 (13y 4m). Tweed analysis 
A second-premolar extraction strategy avoided strong incisor retraction, while balancing the anterior box; the permitted anchorage loss should be of good prognosis for $3^{\text {rd }}$ molar "salvage" (fig. 55 and 56).

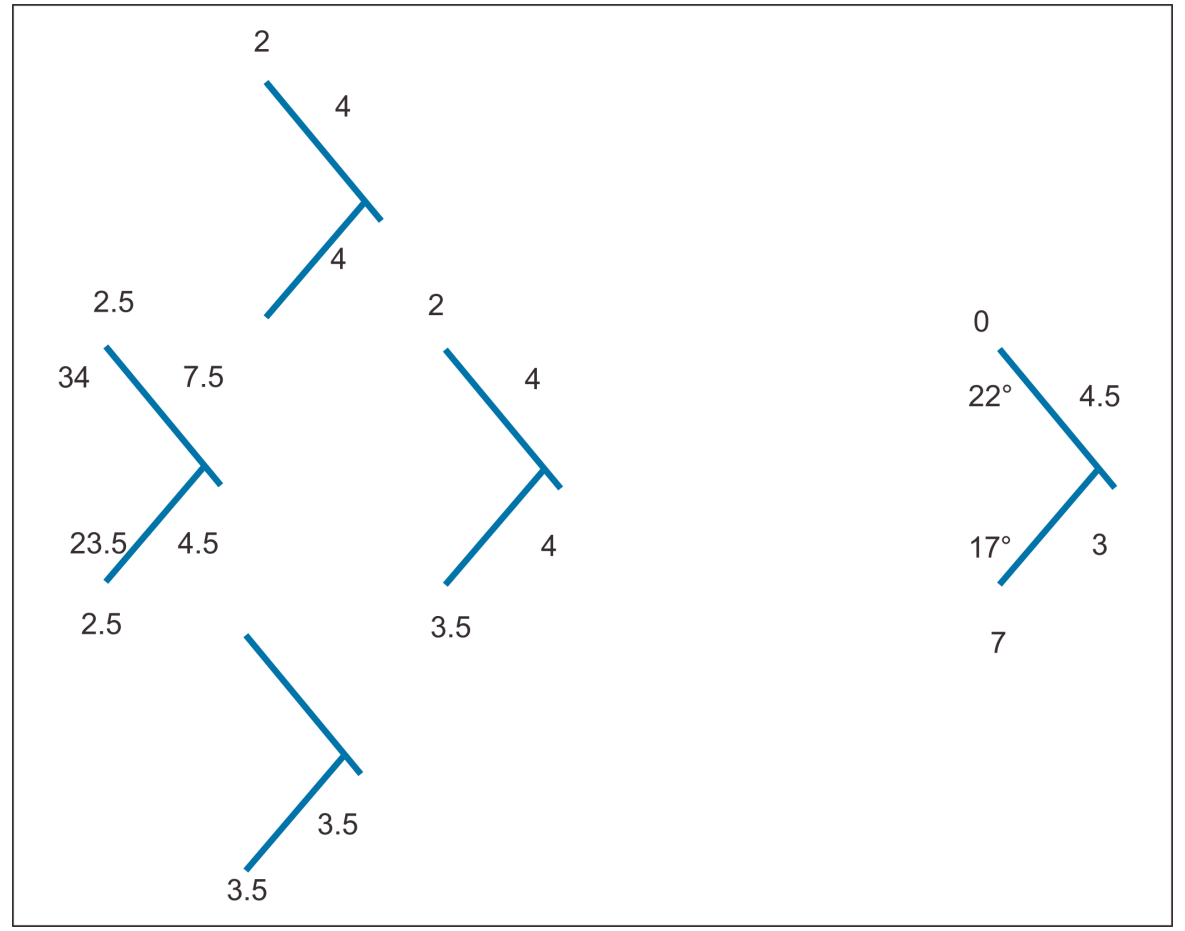

Figure 55

Steiner chevrons. $1^{\text {st }}$ documents, May 2011 (13y 4m).

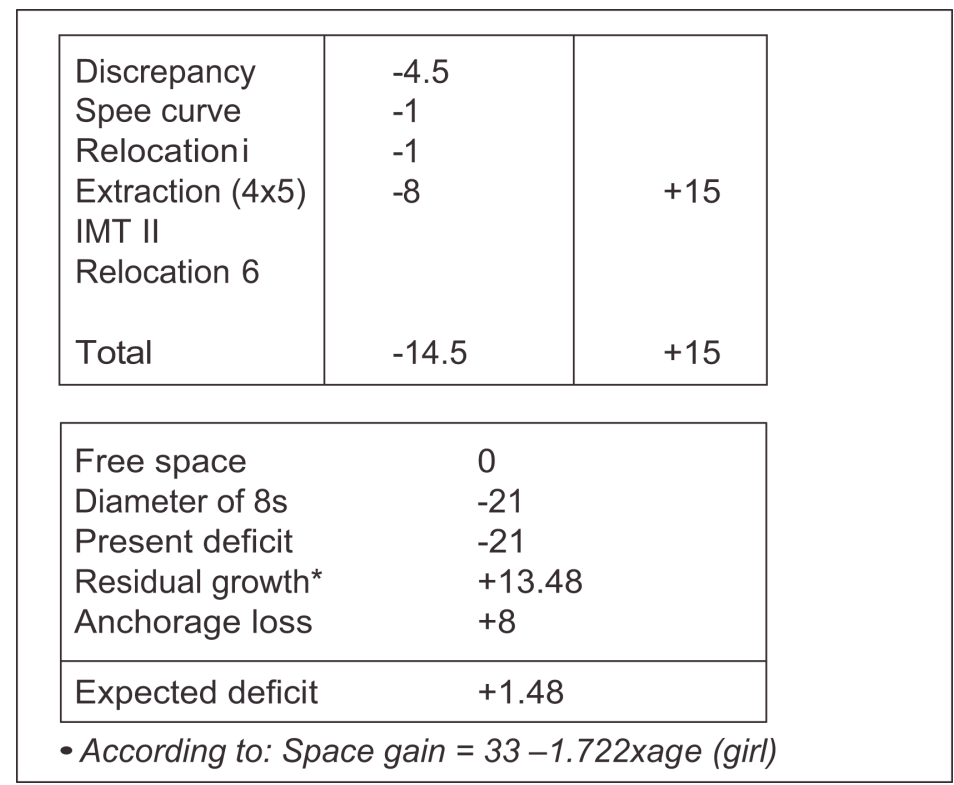

Figure 56

Steiner "box" and posterior space "box". 
Treatment and finishing: April 2012 (14 years 3 months) - November 2014 (16 years 10 months)

The patient was fitted with straight arch brackets with Roth prescription and built-in $-10^{\circ}$ and $-15^{\circ}$ mandibular molar tip-back for better anchorage control (passive self-ligating brackets).

Multibracket treatment was begun in April 2012 (14 years 3 months) and finishing in March 2014 (16 years 2 months) (figs 57 and 60), with mainly $2^{\text {nd }}$ order interventions. Multibracket treatment was completed in November 2014 (16 years 10 months).

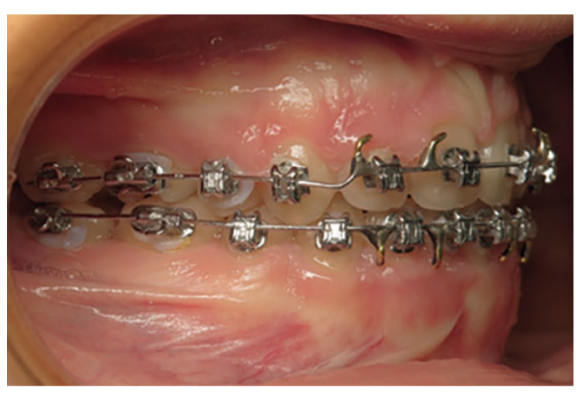

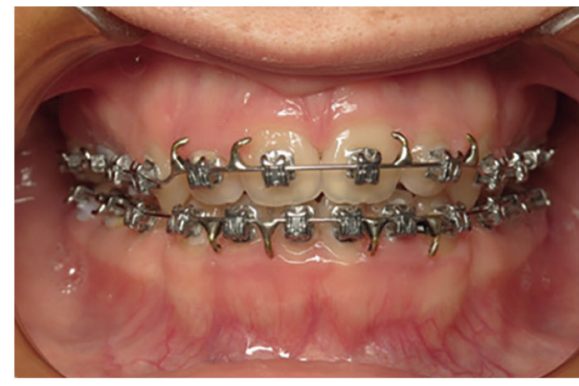

Figure 57

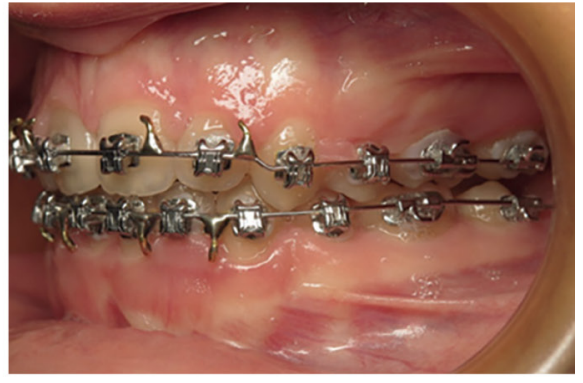

a, b, c: Right, frontal and left vestibular intra-oral views. Start of finishing, March 2014 (16y 2m): superior incisor intrusion steps to avoid contact with inferior brackets and facilitate superior incisor retraction (transient closed bite).

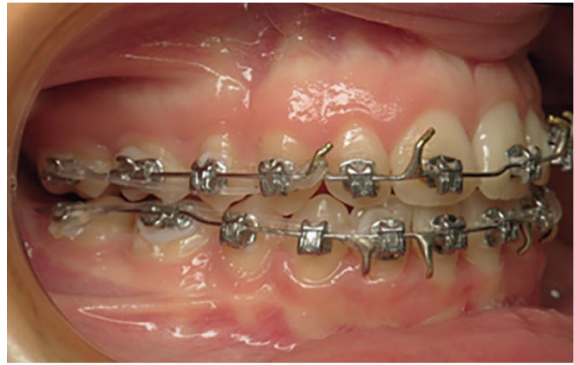

a

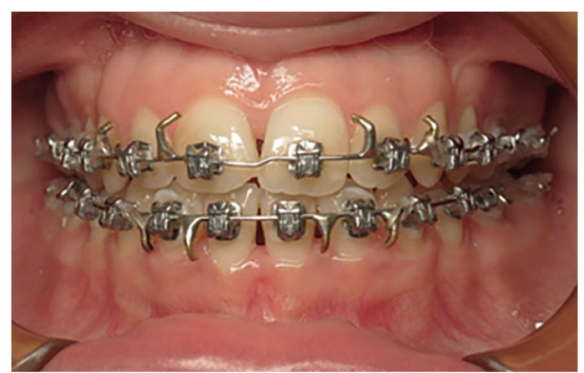

Figure 58

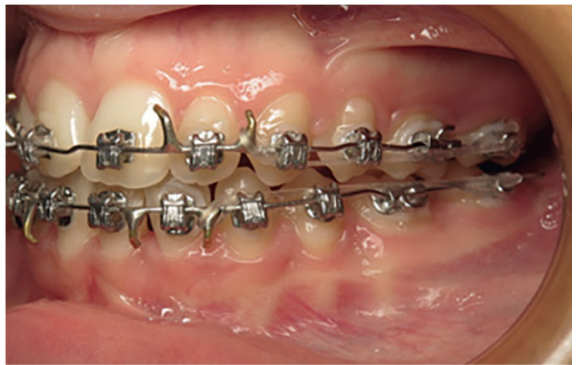

C

a, b, c: Right, frontal and left vestibular intra-oral views. Finishing, August 2014 (16y 7m): suppression of incisor intrusion steps (retraction terminated), correction of 21, intrusion of 15, extrusion of 46.

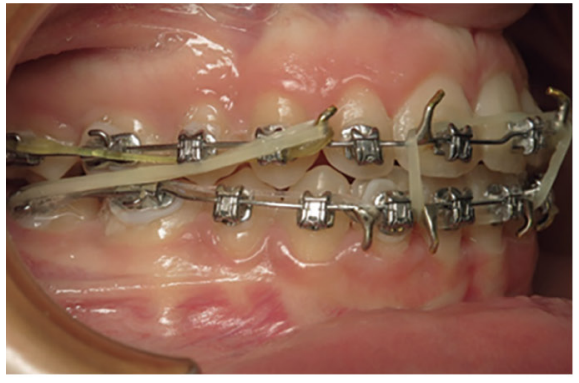

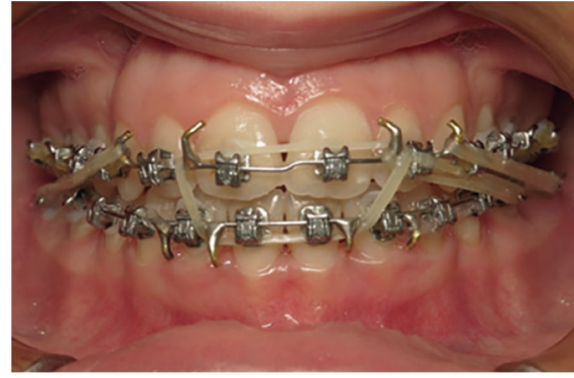

Figure 59

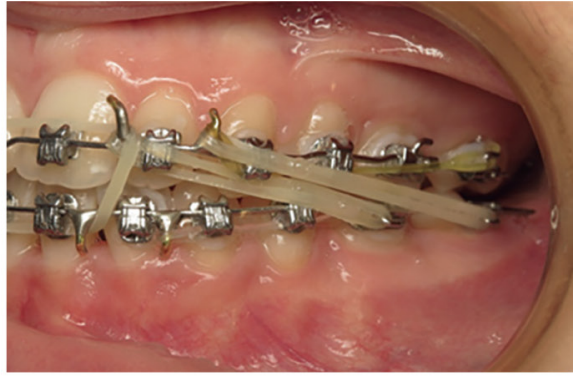

a, b, c: Right, frontal and left vestibular intra-oral views. Finishing, August 2014 (16y 7m): vertical interarcade traction and renewed intermaxillary traction II (insufficient class I/ correction). 
The photographs of the terminal arches show the finishing results (figs 61-65): mainly $2^{\text {nd }}$ order interventions (step, Spee curve, accentuated in maxilla and inverted in mandible, tip- forward on 21, intrusion step-down molar groups with a slight gauge excess etc.) but also 3rd order (reduction of superior incisor torque).

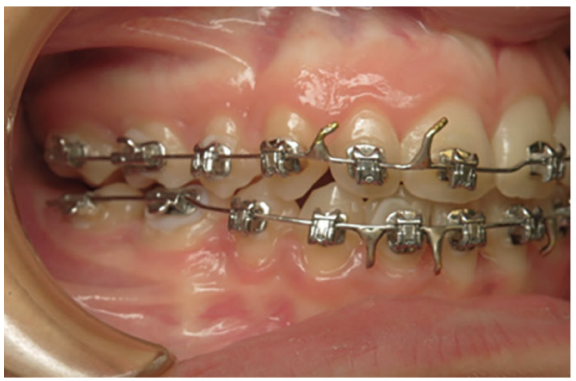

a

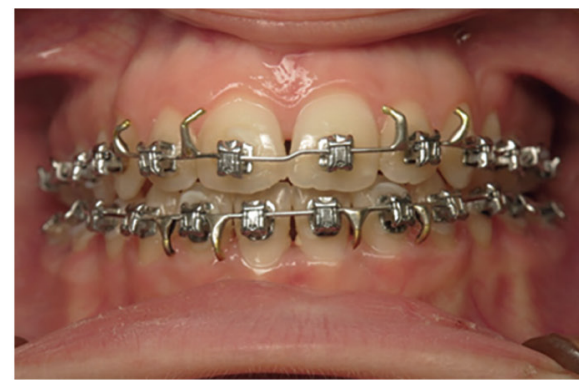

Figure 60 b

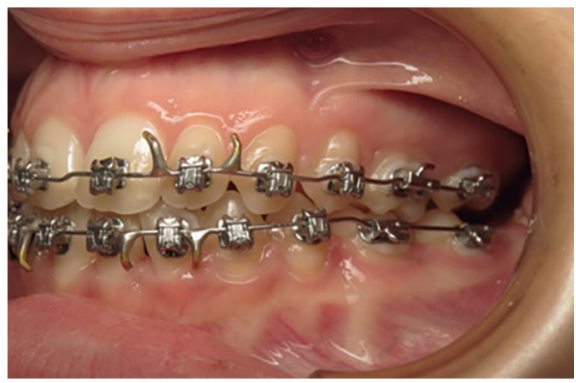

c

a, b, c: Right, frontal and left vestibular intra-oral views. End of finishing, Nov. 2014 (16y 10m).

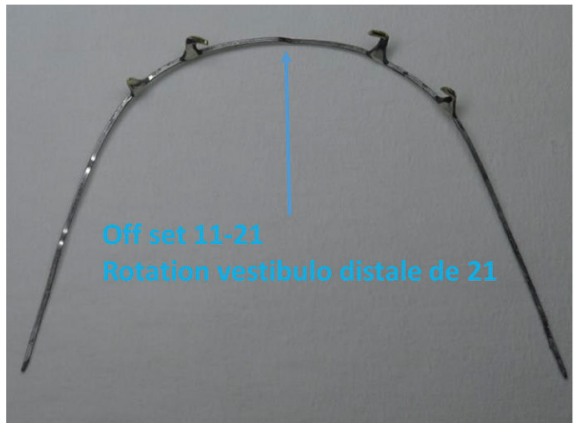

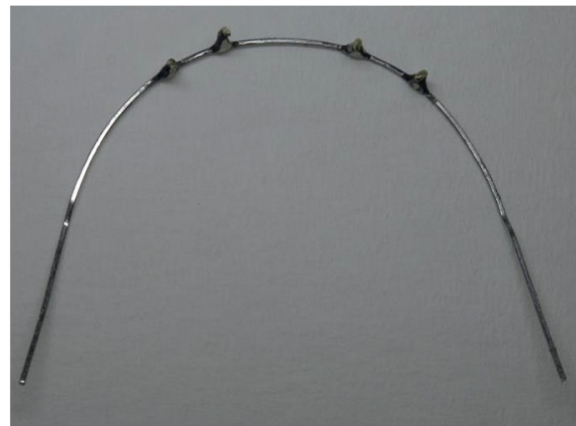

Figure 61

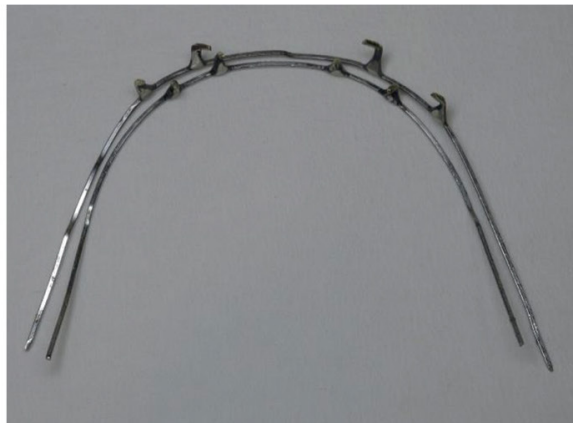

$a, b, c$ : Occlusal views of terminal arches: maxillary, mandibular (upside-down) and coordination. November 2014 (16 years 10 months). Distal vestibular rotation of 21

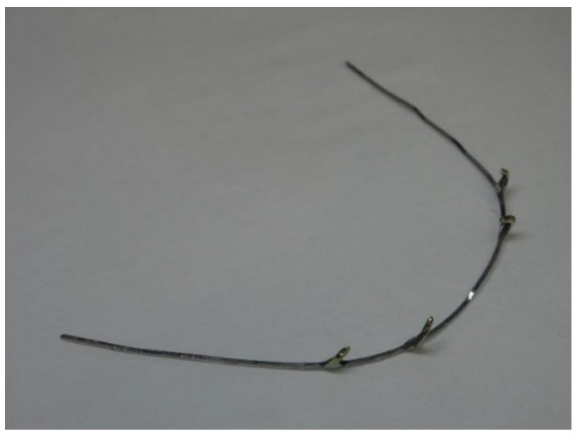

a

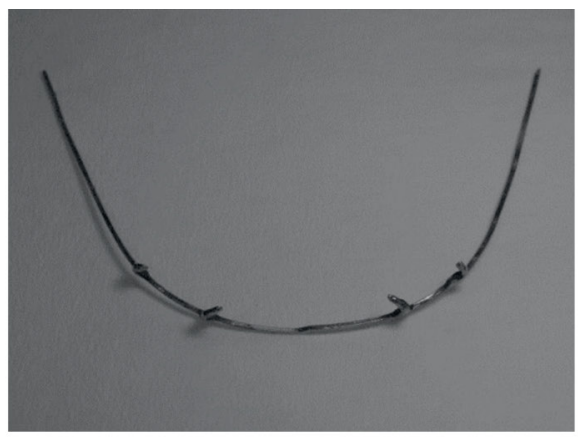

Figure 62

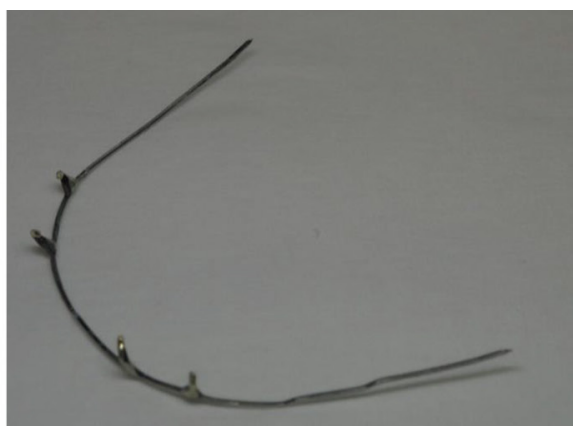

a, b, c: Maxillary terminal arch: right, frontal and left views. November 2014 (16 years 10 months). 


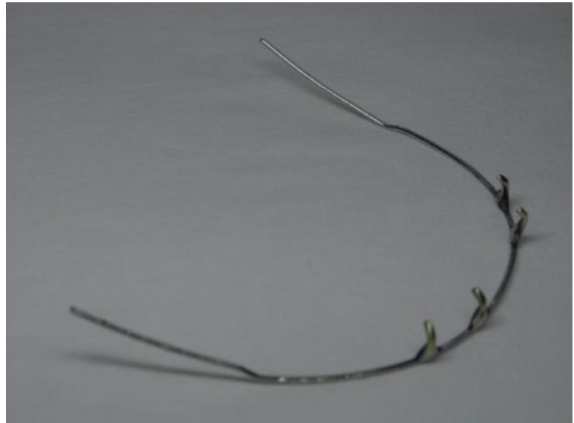

a

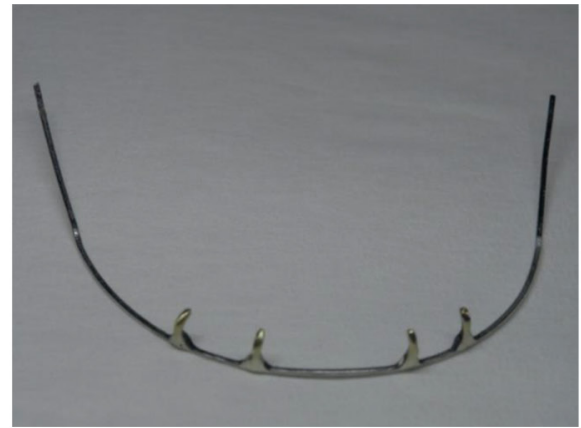

b

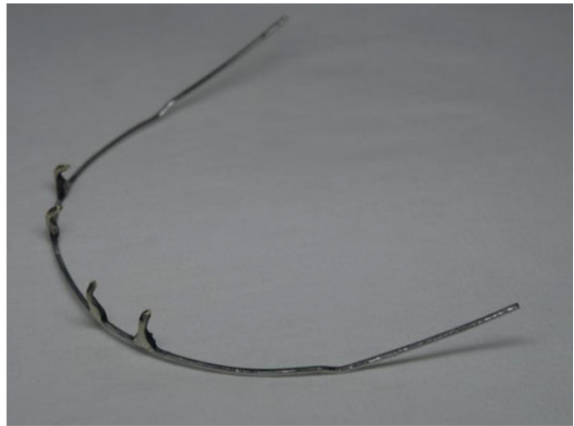

C

Figure 63

a, b, c: Mandibular terminal arch (upside-down): right (left side), frontal and left (right side) views.

November 2014 (16 years 10 months).

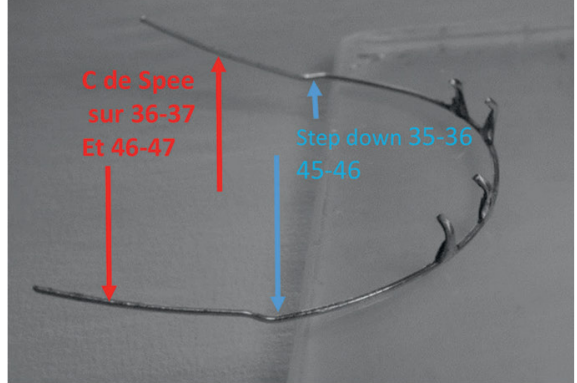

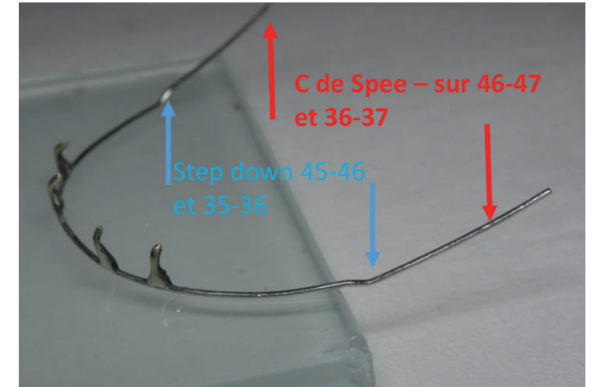

b

Figure 64

a, b: Mandibular terminal arch (upside-down) on glass plate: right (left side), frontal and left (right side) views: evidence of $2^{\text {nd }}$ order. November 2014 (16 years 10 months).

(a) Spee curve on 36-37 and 46-47 / Step-down and step-up on 35-36 and 45-46

(b) Spee curve on 46-47 and 36-37 / Step-up and step-down on 45-46 and 36-37

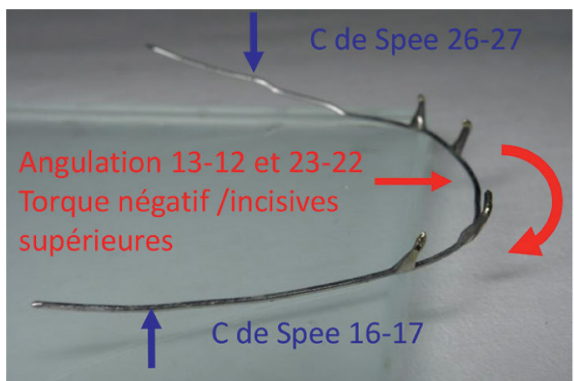

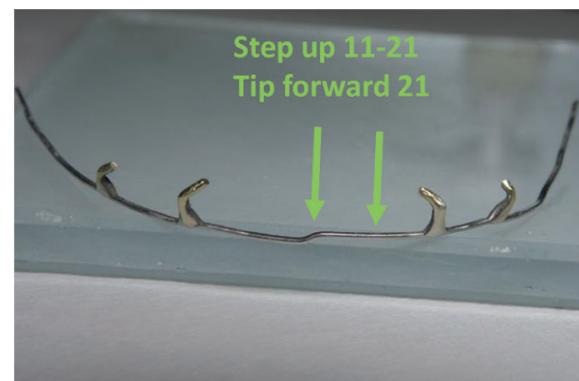

b

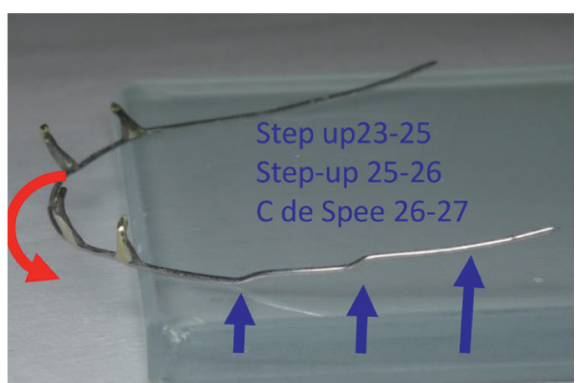

Figure 65

$a, b, c$ : Maxillary terminal arch on glass plate: right, frontal and left views: evidence of $2^{\text {nd }}$ order.

November 2014 (16 years 10 months).

Spee curve 16-17 and 26-27 / Angulation 13-12 and 23-22 / Negative torque on superior incisors /

Step up 23-25 and 25-26. 
End of multibracket treatment documents show over-compensation of linear and angular superior protrusion, guaranteeing stability (from $7.5 \mathrm{~mm} / 34^{\circ}$ to $2.5 \mathrm{~mm} / 18.5^{\circ}$ ) (figs 66 and 67). Rigorous intercuspation, and beaming smile (figs 68, 69 and 70).

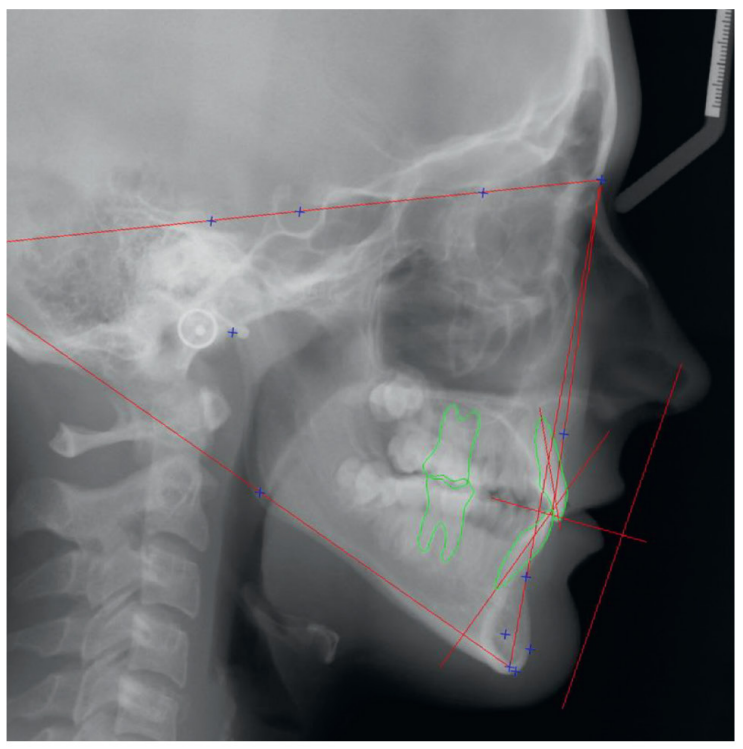

a

\begin{tabular}{|c|c|c|c|c|}
\hline SNA & $82.0^{\circ}$ & \pm 2.0 & 75.6 & -4.4 \\
\hline SNB & $80.0^{\circ}$ & \pm 2.0 & 73.3 & -4.7 \\
\hline ANB & 2. $0^{\circ}$ & \pm 2.0 & 2. 3 & OK \\
\hline SND & $76.0^{\circ}$ & \pm 2.0 & 72.0 & -2.0 \\
\hline SL & 51. $0 \mathrm{~mm}$ & \pm 3.0 & 42.8 & -5.2 \\
\hline SE & 22. $0 \mathrm{~mm}$ & \pm 3.0 & 20.7 & OK \\
\hline GoGn to SN & $32.0^{\circ}$ & \pm 2.0 & 40.9 & 6.9 \\
\hline I to NA $\mathrm{mm}$ & 4. $0 \mathrm{~mm}$ & \pm 2.0 & 2. 6 & OK \\
\hline $\mathrm{i}$ to $\mathrm{NB} \mathrm{mm}$ & 4. $0 \mathrm{~mm}$ & \pm 2.0 & 3.0 & OK \\
\hline Pog to NB & $0.0 \mathrm{~mm}$ & \pm 100.0 & 4. 0 & OK \\
\hline Pog to $i-N B$ & $0.0 \mathrm{~mm}$ & \pm 100.0 & -1.0 & OK \\
\hline I to $N A^{\circ}$ & 22. $0^{\circ}$ & \pm 2.0 & 18.3 & -1.7 \\
\hline i to $N B$ o & $25.0^{\circ}$ & \pm 2.0 & 25.0 & OK \\
\hline I to $i^{\circ}$ & $131.0^{\circ}$ & \pm 2.0 & 134.4 & 1. 4 \\
\hline Occl to SN & $14.0^{\circ}$ & \pm 2.0 & 21.8 & 5. 8 \\
\hline
\end{tabular}

Figure 66

a, b: Teleradiograph with Steiner lines and Steiner cephalometry. November 2014 (16 years 10 months)).

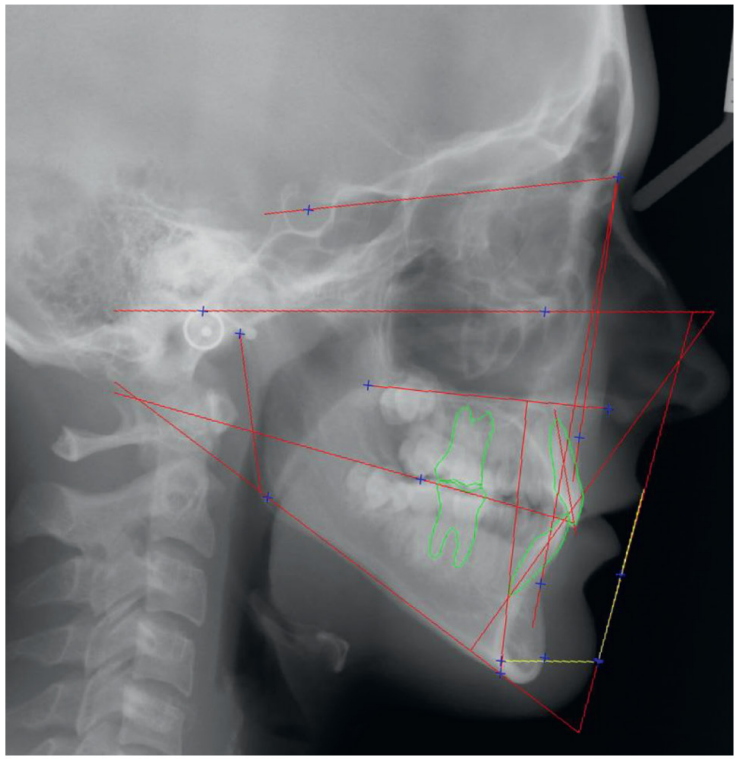

a
Analyse de Tweed :

\begin{tabular}{|l|c|r|r|r|}
\hline Angle FMA & $25.0^{\circ}$ & \pm 5.0 & 36.9 & 6.9 \\
\hline Angle FMIA & $68.0^{\circ}$ & \pm 3.0 & 54.4 & -10.6 \\
\hline Angle IMPA & $87.0^{\circ}$ & \pm 5.0 & 88.7 & OK \\
\hline & & & & \\
\hline Angle SNA & $82.0^{\circ}$ & \pm 2.0 & 75.6 & -4.4 \\
\hline Angle SNB & $80.0^{\circ}$ & \pm 2.0 & 73.3 & -4.7 \\
\hline Angle ANB & $2.0^{\circ}$ & \pm 2.0 & 2.3 & OK \\
\hline AO-BO & $0.0 \mathrm{~mm}$ & \pm 2.0 & -0.6 & OK \\
\hline Occlusal - SN & $14.0^{\circ}$ & \pm 2.0 & 21.8 & 5.8 \\
\hline Occlusal - FH & $10.0^{\circ}$ & \pm 2.0 & 15.7 & 3.7 \\
\hline Inter-incisif & $135.0^{\circ}$ & \pm 3.0 & 134.4 & OK \\
\hline total chin & $11.0 \mathrm{~mm}$ & \pm 5.0 & 16.0 & 0.0 \\
\hline upper lip & $13.0 \mathrm{~mm}$ & \pm 5.0 & 13.4 & OK \\
\hline Angle Z & $78.0^{\circ}$ & \pm 3.0 & 75.0 & 0.0 \\
\hline Nasion - ENA & $56.6 \mathrm{~mm}$ & \pm 10.0 & 51.5 & OK \\
\hline Menton - ENA & $65.7 \mathrm{~mm}$ & \pm 10.0 & 64.0 & OK \\
\hline HFP & $45.0 \mathrm{~mm}$ & \pm 10.0 & 36.2 & OK \\
\hline HFA & $65.0 \mathrm{~mm}$ & \pm 10.0 & 62.1 & OK \\
\hline HFP / HFA & 0.7 & \pm 0.2 & 0.6 & OK \\
\hline
\end{tabular}

Figure 67

a, b: Teleradiograph with Tweed lines and Tweed cephalometry. November 2014 (16 years 10 months).

Tweed analysis

Interincisor

Chin 


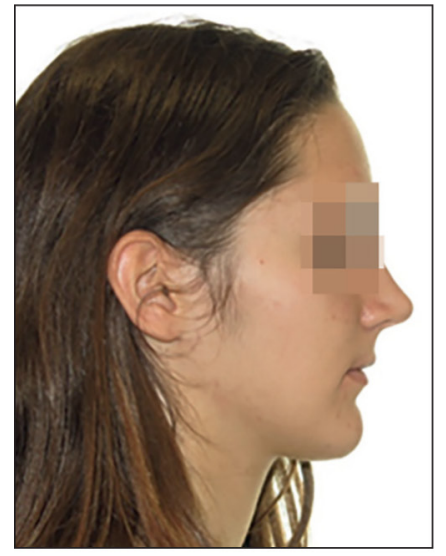

a

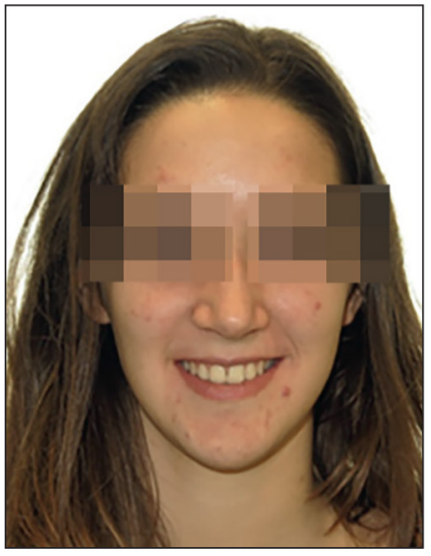

b

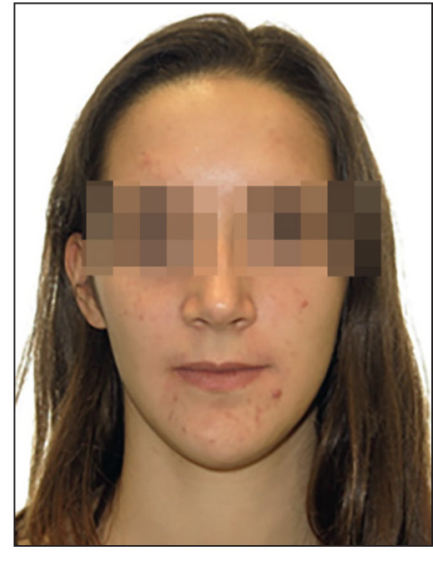

C

Figure 68

a, b, c: Lateral, smile and frontal views. Ablation. November 2014 (16 years 10 months).

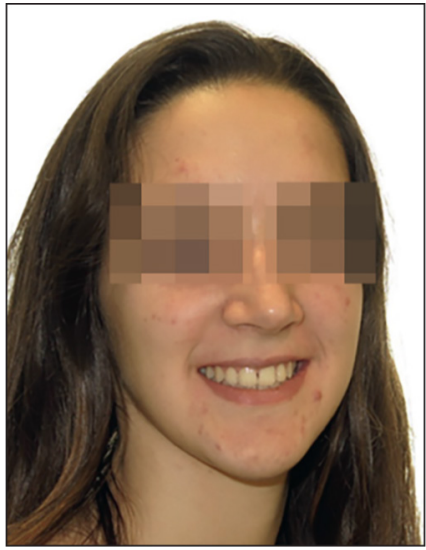

Figure 69

End-of-treatment smile.

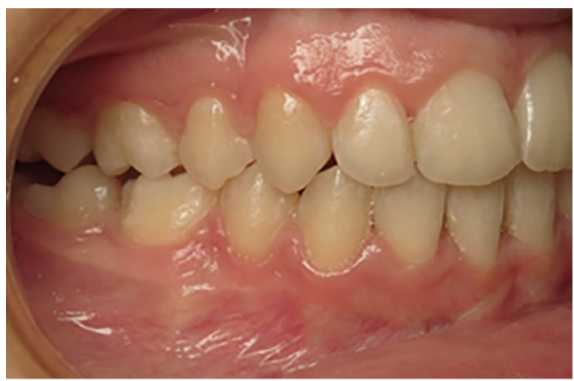

a

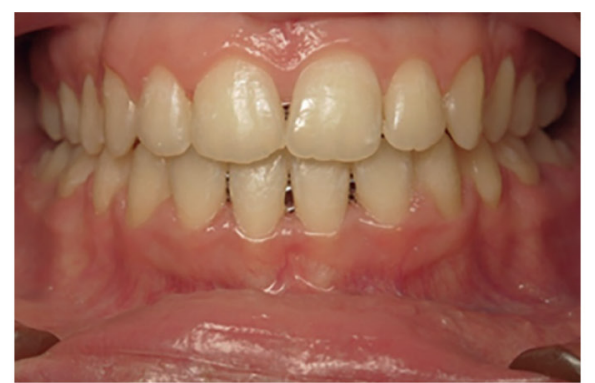

b

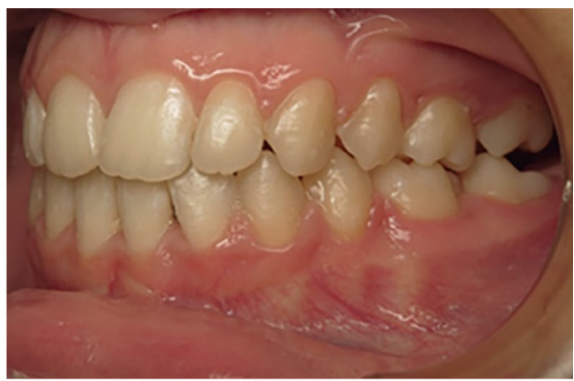

C

Figure 70

a, b, c: Right, frontal and left vestibular intra-oral views. Ablation. November 2014 (16 years 10 months). 
Third-molar progression will be followed up (fig. 71).

Retention comprises a transparent maxillary splint and a metal wire glued to the mandibular ar- cade from 33 to 43 (figs 72 and 73).

Conflict of interest: The author declares no conflict of interest.

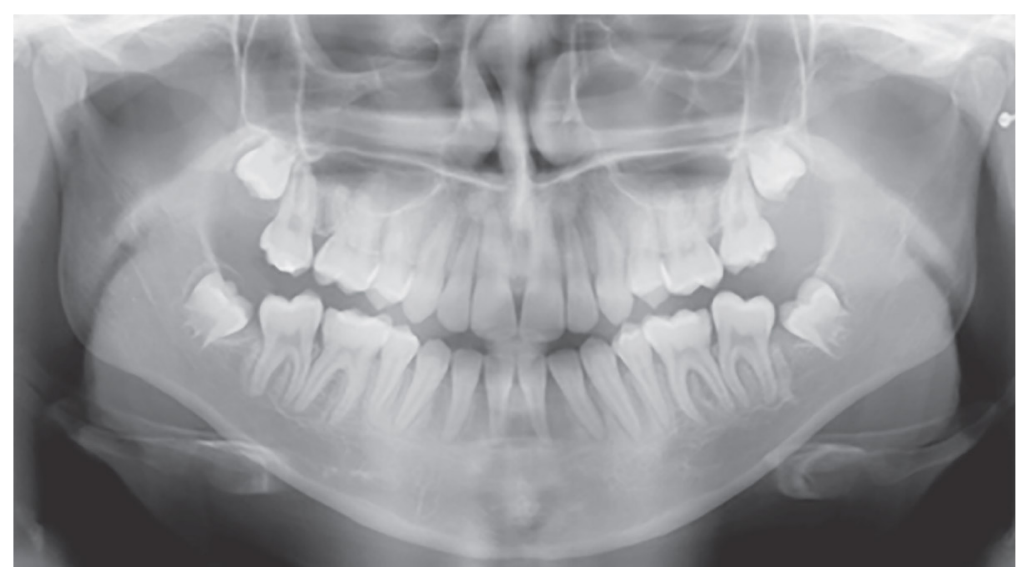

Figure 71

Panoramic end-of-treatment view. November 2014 (16 years 10 months).

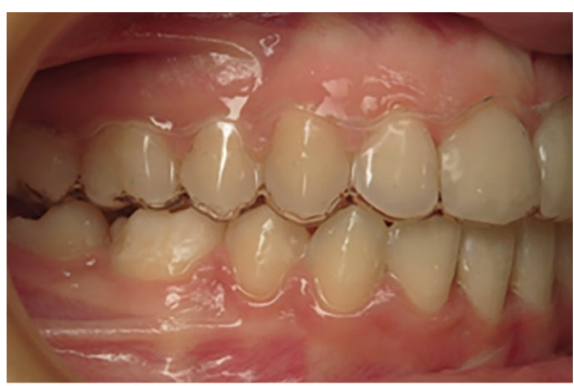

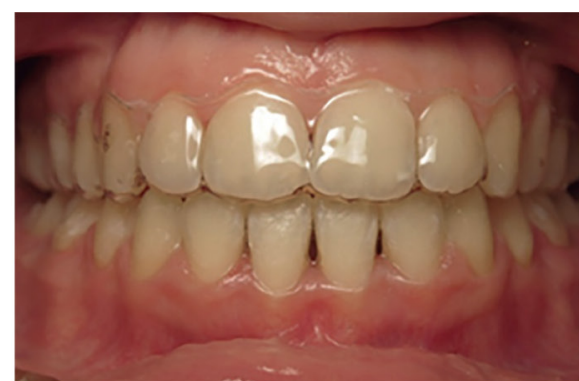

Figure 72

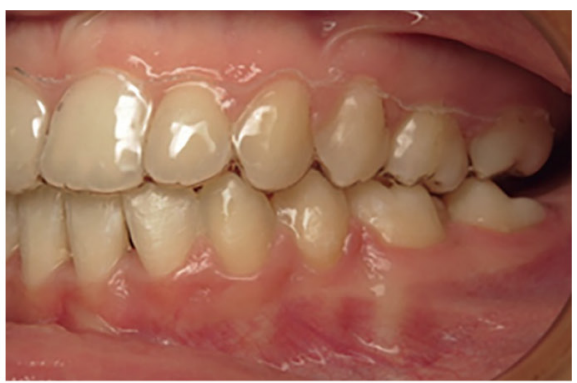

a, b, c: Right, frontal and left vestibular intra-oral views with retention. November 2014 (16 years 10 months).

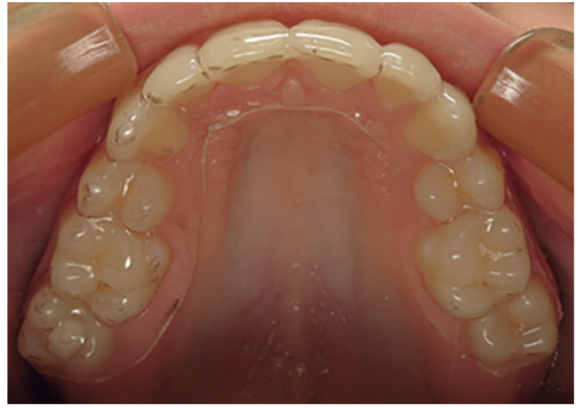

a

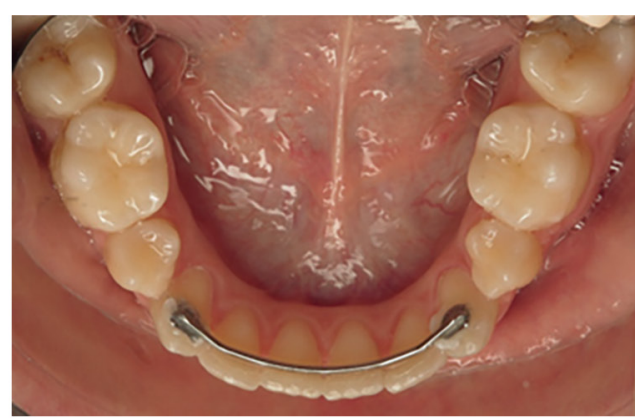

b

Figure 73

a, b: Intra-oral occlusion views, with retention. November 2014 (16 years 10 months). 


\section{REFERENCES}

1. American Board of Orthodontics Grading System for Dental Casts and Panoramic Radiographs. Revised Jjune 2012;1-22.

2. Artun J, Garol J, Little RM. Long-term stability of mandibular incisors following successful treatment of Class II, Division 1 malocclusions. Angle Orthod 1996;66:229238.

3. Blake M, Bibby K. Retention and stability: A review of litterature. Am J Orthod Dentofacial Orthop 1998;114:299-306.

4. Demange Ch. L'inclinaison vestibulo-linguale naturelle des dents. Rev Orthop Dento Faciale 1997;31:473-488.

5. De la Cruz AR, Sampson P, Little RM, Artun J, Shapiro PA. Long-term changes in arch form after orthodontic treatment and retention. Am J Orthod Dentofacial Orthop 1995;107(5):518-530.

6. DeGuzman L, Bahirael D, Vig PS, Weyant RJ, O'Brien K. The validation of the PAR index for malocclusion severity and treatment difficulty. Am J Orthod Dentofacial Orthop 1995;107:172-176.

7. Miyazaki H, Moteji E, Yatabe K, Isshiki Y. Occlusal stability after extraction orthodontic therapy in adult and adolescent patient. Am J Orthod Dentofacial Orthop 1997;112:530537.

8. Ormiston JP, Huang GJ, Little RM, Decker JD, Seuk GD. Retrospective analysis of long-term stable and unstable orthodontic treatment outcomes. Am J Orthod Dentofacial Orthop 2005;128:568-574.

9. Poling R. A method of finishing the occlusion. Am J Orthod Dentofacial Orthop 1999;115:476-487.

10. Richmond $\mathrm{S}$ et al. The development of the PAR index (Peer Aassessment Rating): reliability and variability. European J Orthod 1992;14:125-139.

11. Rothe LE, et al. Trabecular and cortical bone as risk factors for orthodontic relapse. Am J Orthod Dentofacial Orthop 2006;130(4):476-484.

12. Sadowsky C, Schneider BJ, BeGole EA, Tahir E. Long term stability after orthodontic treatment. Non extraction with prolonged retention. Am J Orthod Dentofacial Orthop 1994;106:243-249. 